


\section{A Orientación editorial}

\section{Enfoque y alcance}

La Revista de Arquitectura (ISSN 1657-0308 Impresa y E-ISSN 2357-626X en línea) es una publicación seriada de acceso abierto, arbitrada mediante revisión por pares (doble ciego) e indexada, en donde se publican resultados de investigación originales e inéditos.

Está dirigida a la comunidad académica y profesional de las áreas afines a la disciplina. Es editada por la Facultad de Diseño y el Centro de Investigaciones (CIFAR) de la Universidad Católica de Colombia en Bogotá (Colombia).

La principal área científica a la que se adscribe la Revista de Arquitectura según la OCDE es:

Gran área: 6. Humanidades

Área: 6.D. Arte

Disciplina: 6D07. Arquitectura y Urbanismo

También se publican artículos de las disciplinas como 2A02, Ingeniería arquitectónica; 5G03, Estudios urbanos (planificación y desarrollo); 6D07, Diseño.

Los objetivos de la Revista de Arquitectura son:

- Promover la divulgación y difusión del conocimiento generado a nivel local, nacional e internacional

- Conformar un espacio para la construcción de comunidades académicas y la discusión en torno a las secciones definidas.

- Fomentar la diversidad institucional y geográfica de los autores que participan en la publicación.

- Potenciar la discusión de experiencias e intercambios científicos entre investigadores y profesionales.

- Contribuir a la visión integral de la arquitectura, por medio de la concurrencia y articulación de las secciones mediante la publicación de artículos de calidad.

- Publicar artículos originales e inéditos que han pasado por revisión de pares, para asegurar que se cumplen las normas éticas, de calidad, validez científica, editorial e investigativa.

- Fomentar la divulgación de las investigaciones y actividades desarrolladas en la Universidad Católica de Colombia.
Palabras clave de la Revista de Arquitectura: arquitectura, diseño, educación arquitectónica, proyecto y construcción, urbanismo.

Idiomas de publicación: español, inglés, portugués y francés. Título abreviado: Rev. Arquit.

\section{Titulo corto: RevArq}

\section{Políticas de sección}

La revista se estructura en tres secciones correspondientes a las líneas de investigación activas y aprobadas por la institución, y dos complementarias, que presentan dinámicas propias de la Facultad de Diseño y las publicaciones relacionadas con la disciplina.

Cultura y espacio urbano. En esta sección se publican los artículos que se refieren a fenómenos sociales en relación con el espacio urbano, atendiendo aspectos de la historia, el patrimonio cultural y físico, y la estructura formal de las ciudades y el territorio.

Proyecto arquitectónico y urbano. En esta sección se presentan artículos sobre el concepto de proyecto, entendido como elemento que define y orienta las condiciones proyectuales que devienen en los hechos arquitectónicos o urbanos, y la forma como estos se convierten en un proceso de investigación y nuevo de conocimiento. También se presentan proyectos que sean resultados de investigación, los cuales se validan por medio de la ejecución y transformación en obra construida del proceso investigativo. También se contempla la publicación de investigaciones relacionadas con la pedagogía y didáctica de la arquitectura, el urbanismo y el diseño.

Tecnología, medioambiente y sostenibilidad. En esta sección se presentan artículos acerca de sistemas estructurales, materiales y procesos constructivos, medioambiente y gestión, relacionados con los entornos social-cultural, ecológico y económico.

Desde la Facultad. En esta sección se publican artículos generados en la Facultad de Diseño, relacionados con las actividades de docencia, extensión, formación en investigación o internacionalización, las cuales son reflejo de la dinámica y de las actividades realizadas por docentes, estudiantes y egresados; esta sección no puede superar el $20 \%$ del contenido.

Textos. En esta sección se publican reseñas, traducciones y memorias de eventos relacionados con las publicaciones en Arquitectura y Urbanismo.

\section{A Frecuencia de publicación}

Desde 1999 y hasta el 2015, la Revista de Arquitectura publicó un volumen al año, a partir del 2016 se publicarán dos números por año en periodo anticipado, enero-junio y julio-diciembre, pero también maneja la publicación anticipada en línea de los artículos aceptados (versión Post-print del autor).

La Revista de Arquitectura se divulga mediante versiones digitales (PDF, HTML, XML) e impresas con un tiraje de 700 ejemplares, los tiempos de producción de estas versiones dependerán de los cronogramas establecidos por la editorial.

Los tiempos de recepción-revisión-aceptación pueden tardar entre seis y doce meses dependiendo del flujo editorial de cada sección y del proceso de revisión y edición adelantado.

Con el usuario y contraseña asignados, los autores pueden ingresar a la plataforma de gestión editorial y verificar el estado de revisión, edición o publicación del artículo.
A Canje

La Revista de Arquitectura está interesada en establecer canje con publicaciones académicas, profesionales o científicas del área de Arquitectura y Urbanismo, como medio de reconocimiento y discusión de la producción científica en el campo de acción de la publicación.

\section{Mecanismo}

Para establecer canje por favor descargar diligenciar y enviar el formato: RevArq FP20 Canjes

Universidad Católica de Colombia (2016, julio-diciembre). Revista de Arquitectura, 18(2), 1-136. Doi: 10.14718

ISSN: 1657-0308 E-ISSN: 2357-626X

Especificaciones:

Formato: $34 \times 24 \mathrm{~cm}$

Papel: Mate $115 \mathrm{~g}$

Tintas: Negro y policromía

\section{(A) Contacto}

Dirección postal:

Avenida Caracas No. 46-72. Universidad Católica de Colombia. Bogotá D.C.(Colombia)

Código postal: 111311

Facultad de Diseño, Centro de Investigaciones (CIFAR). Sede El Claustro. Bloque "L", 4 piso, Diag. 46a No. 15b-10. Editor, Arq. César Andrés Eligio Triana

Teléfonos: +57 (1) 3277300 - 3277333

Ext. 3109; 3112 o 5146

Fax: +57 (1) 2858895

Correo electrónico:

revistadearquitectura@ucatolica.edu.co cifar@ucatolica.edu.co

\section{Página WEB}

www.ucatolica.edu.co vínculo Revistas científicas http://publicaciones.ucatolica.edu.co/revistas-cientificas http://editorial.ucatolica.edu.co/ojsucatolica/revistas ucatoli$\mathrm{ca} /$ index.php/RevArq 


\section{CONTENDO}

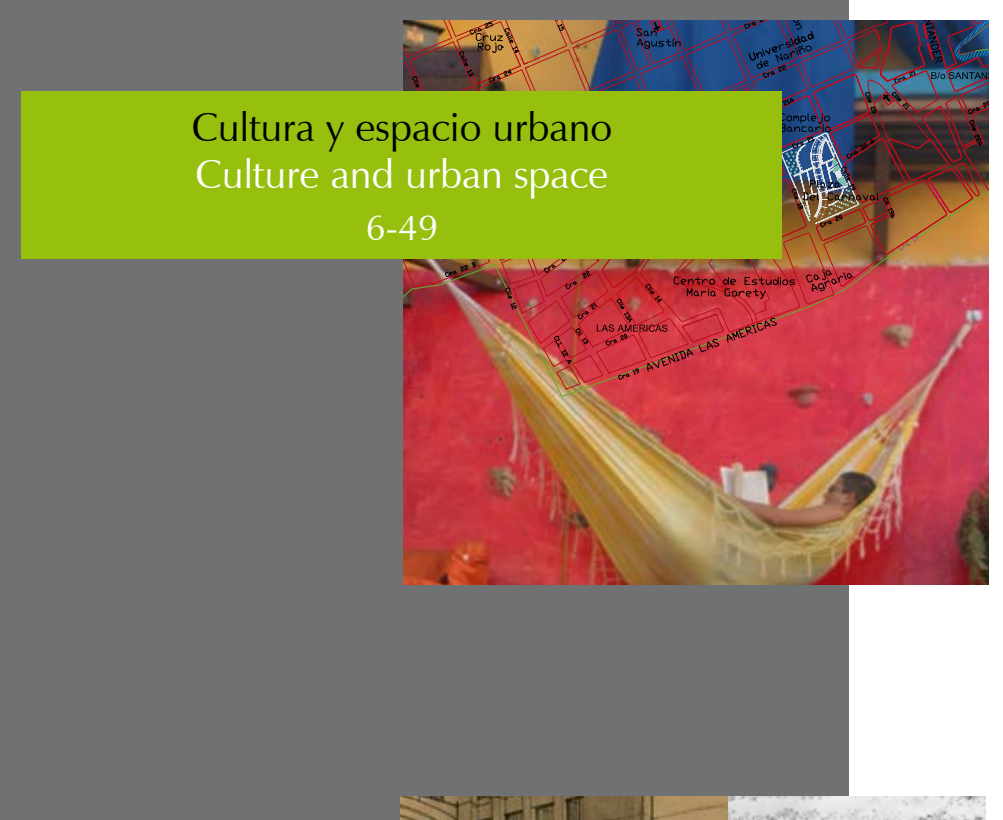

Estructura de indicadores de habitabilidad del espacio público en ciudades latinoamericanas

Pablo Páramo, Andrea Burbano, Diana Fernández-Londoño Pág. 6

Além do público/privado

Intervenções temporárias e criação de

espaços coletivos no Rio de Janeiro

Adriana Sansão-Fontes, Aline Couri-Fabião

Pág. 27

Conservar o renovar: dinámicas de construcción en el centro histórico de tres ciudades intermedias patrimoniales

Una mirada a través de las licencias urbanísticas

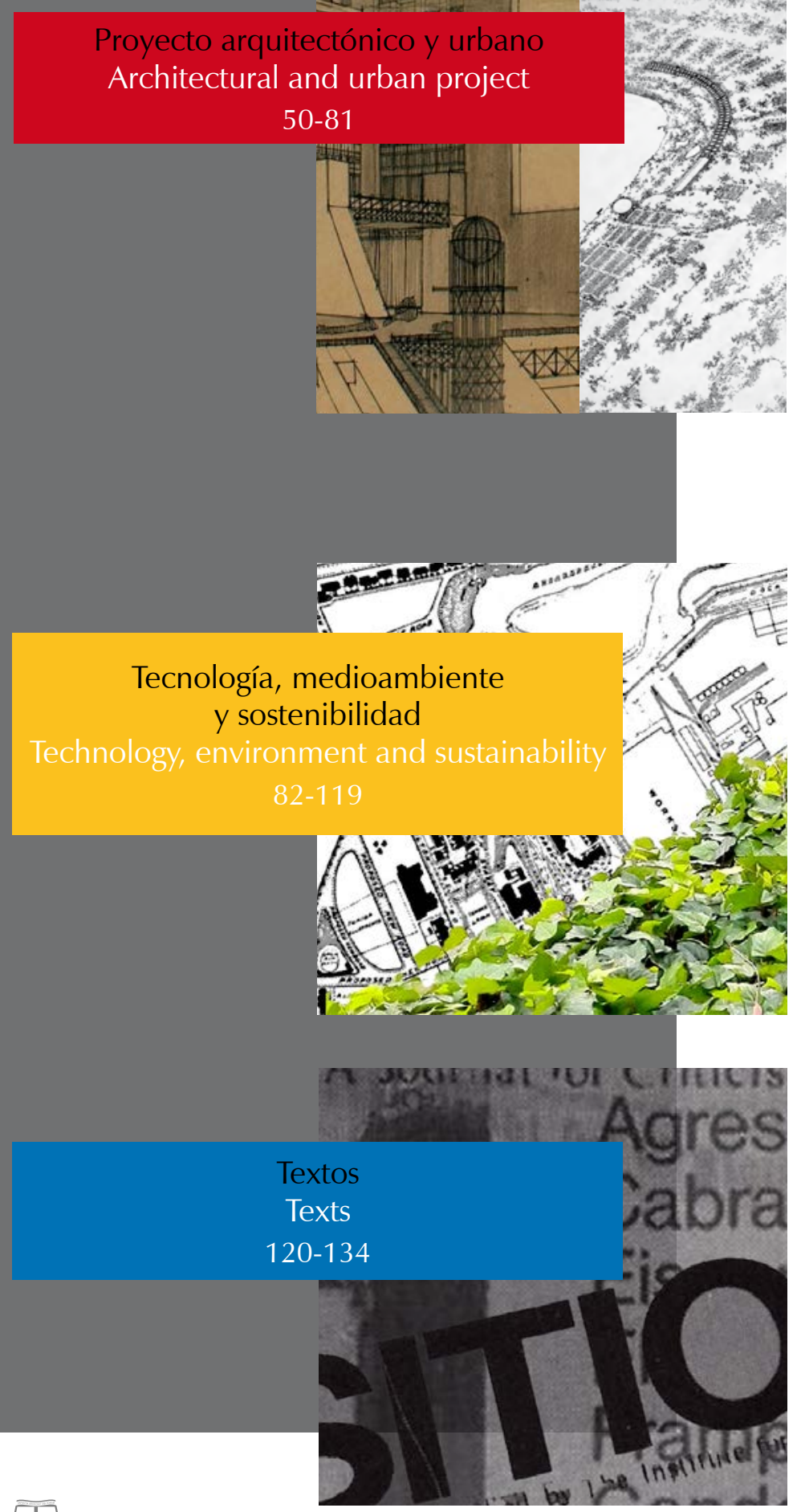

El paisaje del hábitat horizontal:

la Unidad del Tuscolano en Roma y el Poblado de Entrevías en Madrid

Federico Colella

Evolución paralela del relato fílmico y la arquitectura de los cines entre 1900 y 1930

Atención especial al caso español

Ana C. Lavilla-Iribarren

El plan, acto mesiánico del proyectista

La situación histórica del diseño en

la utopía modernizante

Valentina Mejía-Amézquita, Adolfo León Grisales-Vargas Pág. 71

Resiliencia a inundaciones:

nuevo paradigma para el diseño urbano

Luis Fernando Molina-Prieto

Pág. 82

Acceso solar en la arquitectura y la ciudad

Aproximación histórica

Ricardo Franco-Medina, Pedro Juan Bright-Samper

Pág. 95

\section{Campus universitario sustentable}

Lina Johanna Zapata-González, Andrés Quiceno-Hoyos, Luisa Fernanda Tabares-Hidalgo

La crítica arquitectónica como objeto de investigación [La critique architecturale, objet de recherche]

Hélène Jannière

Traductores: Andrés Ávila-Gómez, Diana Carolina Ruiz Pág. 120 


\section{El paisaje del hábitat horizontal:}

\section{la Unidad del Tuscolano en Roma y el Poblado de Entrevías en Madrid}

\section{Federico Colella}

Universidad Politécnica de Madrid. Madrid (España)

Departamento de Proyectos Arquitectónicos (DPA), Escuela Técnica Superior de Arquitectura de Madrid (ETSAM)

\section{Colella Castro, E. (2016). El paisaje del hábitat horizontal: la Uni- dad del Tuscolano en Roma yel Poblado de Entrevías en Madrid. Revista de Arquitectu- ra, 18(2), 50-59. doi:10.14718/ RevArq.2016.18.2.5}

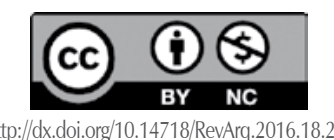

Arquitecto, Universidad RomaTre (Italia).

Doctorando, Departamento de Proyectos Arquitectónicos (DPA) ETSAM-UPM, Madrid (España).

Docente titular, Proyectos Arquitectónicos en la Universidad Anáhuac México sur (UAS) (México).

Arquitecto en oficinas internacionales de arquitectura en Italia, España y México.

Europan (20I3). Primer lugar. Proyecto: "Paths". Arquitectos Federico Colella, Hugo Vargas

http://orcid.org/0000-0003-0453-3093

federico.colella@hotmail.com - f.colella@alumnos.upm.es

\section{Resumen}

El análisis comparativo entre la Unidad del Tuscolano de Adalberto Libera y el poblado de Entrevías de Francisco J. Sáenz de Oíza, evidencia estrategias comunes de diseño enfocadas en establecer un fuerte vínculo entre arquitectura, paisaje y territorio en los diferentes contextos de actuación: Roma y Madrid. El objetivo es investigar las estrategias de diseño de estos asentamientos, los "hábitats horizontales": conjuntos de baja altura y alta densidad que integran las viviendas con el paisaje, lo artificial con lo natural. El diseño del trazado determina la gran porosidad de los conjuntos que se caracterizan por la presencia de plazas públicas, calles peatonales y patios privados. Libera y Sáenz de Oíza desarrollan un paisaje autóctono, a través de un proyecto en el cual prevalece la matriz cultural mediterránea y establecen una fuerte conexión con el lugar concibiendo las unidades habitacionales como topografías artificiales que se adaptan a las estructuras ambientales existentes.

Palabras clave: medio ambiente, hábitat, vivienda social, Adalberto Libera, Sáenz de Oíza.

\section{The landscape of horizontal habitats: The Tuscolano Unit in} Rome and the Village of Entrevías in Madrid

\section{Abstract}

The comparative analysis between the Tuscolano Unit designed by Adalberto Libera and the Village of Entrevías designed by Francisco J. Sáenz de Oíza gives evidence of common design strategies that focused on establishing a strong link between architecture, landscape, and territory in their different contexts of action: Rome and Madrid. The objective is to investigate the design strategies of these housing units called "horizontal habitats:" residential complexes of low height and high density that integrate houses with the landscape, the artificial with the natural. The design of the layout determines the great porosity of the complexes, characterized by the presence of public squares, pedestrian streets, and private backyards. Libera and Sáenz de Oíza developed an autochthonous landscape, through a project in which the Mediterranean cultural origin prevails, and they established a strong connection with the place by conceiving the housing units as artificial topographies that are adapted to the existing environmental structures.

Keywords: Environment, habitat, social housing, Adalberto Libera, Sáenz de Oíza. 


\section{Introducción}

El presente artículo es parte del trabajo de investigación "Hacia una arquitectura aumentada. Territorio, iconografía y mapas neorrealistas de Roma y Madrid, 1943-1963", desarrollado dentro del programa "Teoría y práctica del proyecto", de la Escuela Superior de Arquitectura de Madrid, en el cual se investigan la arquitectura, el territorio y el paisaje urbano de la posguerra en las capitales española e italiana, bajo un enfoque interdisciplinario.

En los aspectos relativos a la dimensión paisajística, al diseño medioambiental y a la capacidad de relacionarse con el territorio en gran escala, hemos podido detectar los más relevantes puntos de contacto entre la Unidad del Tuscolano de Libera y el Poblado dirigido de Entrevías de Sáenz de Oíza (Colella, 2015) dos proyectos habitacionales que, a pesar de la época de realización - la mitad de los años cincuenta del siglo pasado - proponen paradigmas actuales en el ámbito del diseño de la vivienda colectiva. En los dos conjuntos, el proyecto del paisaje no se considera como un aspecto secundario, como "espacio libre" entre lo construido que es necesario completar a través de un diseño más o menos coherente con la arquitectura desarrollada, sino como parte integrante del trazado generador que define el emplazamiento de cada propuesta. Un proyecto que recompone elementos naturales y artificiales, en búsqueda de una continuidad, una analogía con el paisaje existente, los territorios de Roma y Madrid.

Se utilizan como herramienta de diseño las estructuras ambientales propias del lugar para desarrollar lo que en este trabajo de investigación definimos utilizando la palabra hábitat, un fragmento de ciudad que contribuye a su funcionamiento general en el marco de una nueva sensibilidad de la disciplina arquitectónica; una ciudad que, como explica el arquitecto Juan Herreros, ya no se puede describir con "las herramientas del urbanismo tradicional sino con las de la geografía" (2006); se trata de una "geografía infraestructural" un término que quiere expresar una nueva visión del concepto de sostenibilidad que va más allá de las escalas, en donde el proyecto de arquitectura contiene implícitamente un proyecto territorial.

Podemos hablar de estos aspectos bajo otro enfoque crítico, utilizando lo que Benevolo define con el término "ciudad-paisaje" en las conclusiones de su libro Le origini dell'architettura. En este ensayo de 2002, el historiador y crítico italiano habla de los valores de las arquitecturas primitivas en la capacidad de establecer un con- tacto profundo con el paisaje a una escala territorial, una capacidad que hemos perdido y que es necesario recuperar como herramienta para los proyectos urbanos y arquitectónicos del siglo XXI: "Se trata de realizar una conurbación -la ciudad-paisaje - que sea un organismo completo, con la complejidad que distinguía la ciudad histórica dilatada, pero también en la dimensión paisajística, con la sabiduría que caracterizaba a las culturas pre-urbanas" (Benevolo y Albrecht, 2002, p. 263).

Lo que auspicia Benevolo para la cultura del nuevo Milenio es una recuperación histórico-crítica de esta sensibilidad "primitiva", para el desarrollo de una nueva tipología de proyectos que, como los conjuntos del Tuscolano y de Entrevías, sean capaces de relacionarse con el territorio y con el paisaje a gran escala, estableciendo una fuerte conexión entre el lugar y la comunidad que lo ocupa. Se trata de un nuevo campo de investigación en la vivienda, que no se limita exclusivamente al estudio tipológico, al análisis de los fenómenos arquitectónicos, sino que considera las posibilidades que tienen los conjuntos habitacionales de "generar paisaje", de ser "hábitats sensibles" hacia el medio ambiente y las culturas autóctonas (Figuras 1 y 2).
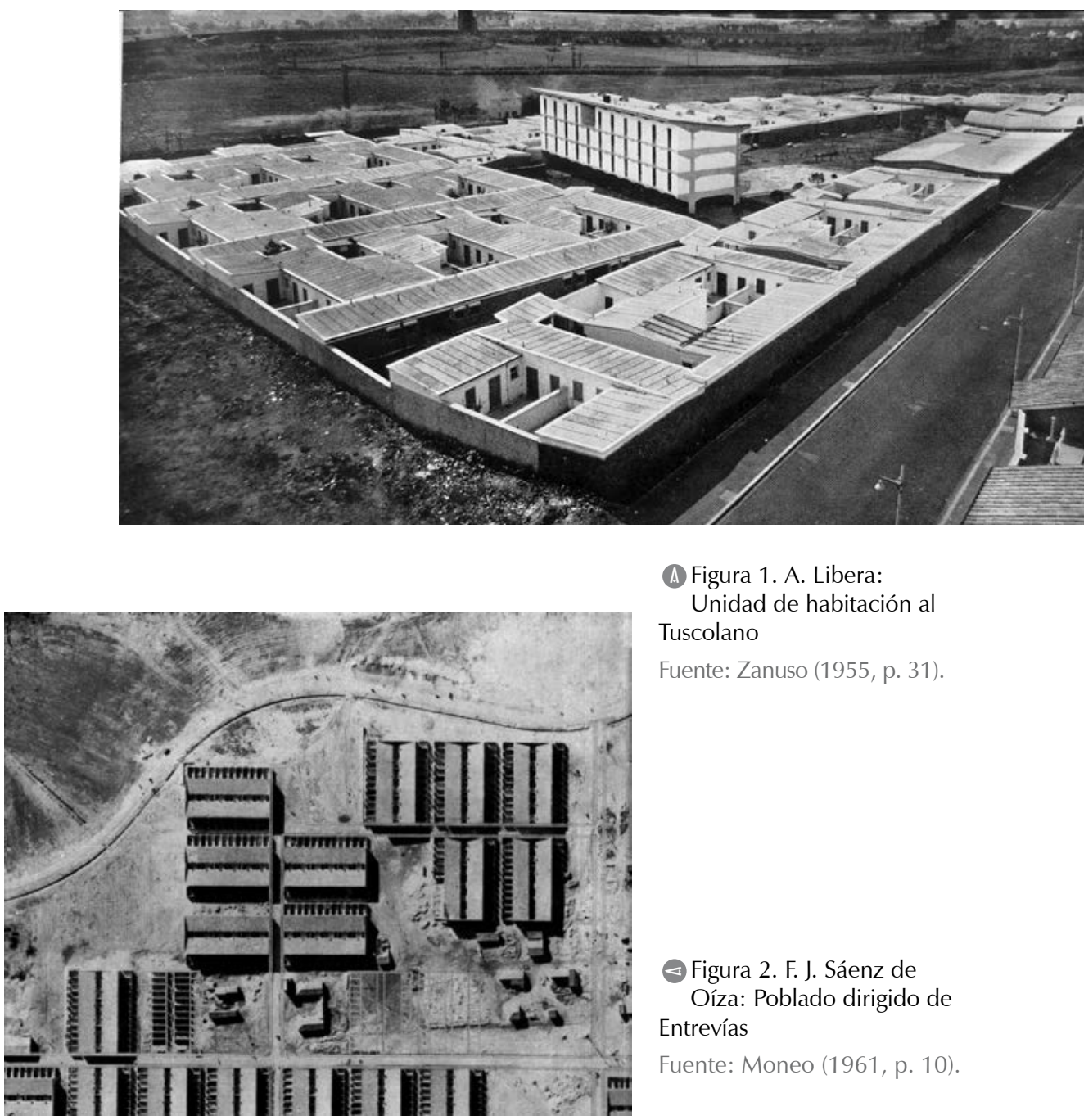

A Figura 1. A. Libera:

Unidad de habitación al Tuscolano

Fuente: Zanuso (1955, p. 31).

Figura 2. F. J. Sáenz de

Oíza: Poblado dirigido de Entrevías

Fuente: Moneo (1961, p. 10). 


\section{Metodología}

En este trabajo de investigación, el análisis comparativo de La Unidad de Libera en el barrio Tuscolano en Roma (1950-1955) y del Poblado dirigido en el barrio de Entrevías en Madrid (1956), evidencia los factores dependientes de los distintos contextos -italiano y español- y permite también focalizar los puntos de contactos que nos ayudan en determinar algunas características generales de lo que definimos "hábitat horizontal". En esta locución, el término "hábitat", como ya hemos analizado, indica la fuerte conexión que en estos conjuntos se establece entre el territorio, con sus estructuras físicas y el hombre con sus actividades y relaciones sociales. El adjetivo "horizontal" se refiere a la vivienda en la cual prevalece esta dimensión respeto a la vertical, y se crea una fuerte conexión con el suelo y la vida de sus habitantes; actualmente este modelo se define como vivienda de baja altura y alta densidad (BAAD).

El modelo del hábitat horizontal tiene su origen en los estudios sobre ciudad-jardín de Howard, Unwin y Soria, y Mata a final del siglo XIX, investigaciones que serán retomadas hacia el 1930 por Hilberseimer y por Giuseppe Pagano en el 1940. El urbanista alemán, junto a Mies van de Rohe, desarrollará la estructura de la unidad de asentamiento, célula básica de una nueva metrópoli de baja altura que desarticula la ciudad distribuyendo la edificación en el paisaje. Este nuevo modelo supera el modelo tradicional de la ciudad-jardín al ser caracterizado por un aprovechamiento del suelo comparable al de un centro urbano. La misma lógica de aplicación de una densidad media será utilizada por Pagano

planeamiento de la ciudad de Chicago

Fuente: Hilberseimer (1944 p. 146). junto a Diotallevi y Marescotti en el proyecto de "la ciudad horizontal" que propone un tapiz de viviendas con patio, aplicable también en sustitución de tejidos urbanos de la ciudad histórica (Pagano, Diotallevi y Marescotti, 1940). Estos estudios tendrán en Europa muy pocas aplicaciones prácticas: en la reconstrucción de la posguerra triunfará la unidad de habitación homogénea alta, la ciudad por bloques lineales de más de tres niveles.

Investigaciones recientes se han enfocado, sobre todo, en los aspectos medioambientales y ecológicos de la propuesta urbana y territorial de Hilberseimer, "la metrópolis como ciudad jardín", subrayando también la fundamental colaboración del urbanista alemán con el paisajista Alfred Caldwell (Llobet i Ribeiro, 2008). Este aspecto es lo que también se ha señalado como uno de los puntos de mayor contacto entre las dos propuestas analizadas en Roma y Madrid (Figura 3).

Libera y Oíza, partiendo de dos contextos distintos, la Italia y la España de los años cincuenta, serán los dos primeros -y entre los pocos en Europa- que llevarán los estudios teóricos de Hilberseimer a la realidad de la construcción ofreciendo modelos alternativos a los que prevalecerán en sus respectivos países.

Para el desarrollo de la comparación analítica de nuestros dos casos de estudio hemos utilizado un sistema de acercamiento progresivo de tipo escalar: desde la escala geografico-territorial hasta la escala de la celula, estableciendo relaciones de tipo transescalar e interescalar que incrementan el nivel de profundidad de los análisis. Se han enfocado tanto los estudios cuantitativos como los cualitativos, en los aspectos de diseño que más están relacionados con el medio ambiente, el territorio y el paisaje. Para una comparación más apropiada, se ha limitado la comparación a la tercera fase del Poblado dirigido de Entrevías que tiene dimensiones parecidas a las de la Unidad del Tuscolano de Libera: alrededor de 3,5 hectáreas.

\section{Resultados: el paisaje del hábitat horizontal}

\section{Paisajes neorrealistas}

A finales de los años cuarenta, los dos países se caracterizan por condiciones sociales y económicas parecidas de gran pobreza, a pesar de situaciones políticas diametralmente opuestas: la dictadura en España y la democracia en Italia. Es la época de la cinematografía Neorrealista que se desarrolla en Italia y tendrá su influencia en el cine español de la época (Baldellou, 1995). 
Es en este clima que florecen las políticas habitacionales de los dos países: el plan INA-casa en Italia en 1949, y el Plan Nacional de la Vivienda (PNV), en 1955 en España. Dentro de estos programas, que querían solucionar el problema de la ocupación a través de la construcción de nuevas viviendas — sobre todo en Italia- y acabar con el chabolismo — más en España-, se desarrollaron la Unidad de habitación horizontal del Tuscolano y el Poblado dirigido de Entrevías. La macroestructura geográfica común, el mediterráneo, determina algunos aspectos ambientales y culturales importantes en los dos proyectos: el clima, la sociabilidad de los habitantes y el valor de la familia, como ideas a la base de conjuntos arquitectónicos que valoran la vida al aire libre, la calle y la privacidad del espacio doméstico.

\section{Escala territorial}

El origen volcánico de todo el sector suroriental de la capital italiana, la orografía baja, y su cercanía al mar, constituyen las diferencias más evidentes con el territorio de Madrid. En esta parte del territorio romano las antiguas actividades eruptivas han producido la colada de lava que representa la condición geológica del terreno sobre el cual se asienta la Unidad de habitación del Tuscolano ${ }^{1}$; la constante y leve pendiente hacia el norte desde las bases del antiguo volcán Laziale es testimonio de este origen.

La capital española es una ciudad que pertenece al sistema orográfico de la meseta central, con una altitud sobre el nivel del mar de casi 700 metros. La estructura geológica de las terrazas aluviales pertenecientes al río Manzanar, con pendientes máximas del 10\%, caracteriza este sector sureste de la ciudad y constituye el sistema topográfico sobre el cual se asientan las Unidades de Entrevías. La naturaleza aluvial de las terrazas determina el tipo de terreno de materia yesosa (Sáenz de Oíza, Sierra Nava y Alvear Criado, 1956). Una ciudad lejos del mar, con la Sierra a sus espaldas —en el norte_-; una ciudad protegida por las montañas, como en las ciudades árabes.

Diferentes los climas en los dos contextos: seco y continental en Madrid, con lluvias escasas, más templado y húmedo el romano, con más precipitaciones.

El de Tuscolano es un territorio de agua; la presencia en el parque en frente de la Unidad de los restos del acueducto romano, el Acueducto Claudio, es testimonio de una fuerte relación entre la tierra y este medio, tan importante en el desarrollo de la ciudad de Roma. La presencia del Manzanares no evita que el de Entrevías sea un "paisaje seco"; como escribe Moneo al describir el territorio de esta zona de Madrid en la revista Hogar y Arquitectura (Figuras 4 y 5).

Todo a nuestro alrededor está como quemado: no crece la hierba. Una acacia empolvada. Postes de alta y baja. Los silbidos del tren. Los gritos de los niños. Vendedores de agua y de tomate. Al fondo el cerro de los Ángeles, como azul y el murmullo del Madrid, como un mar (Moneo, 1961, p. 7).

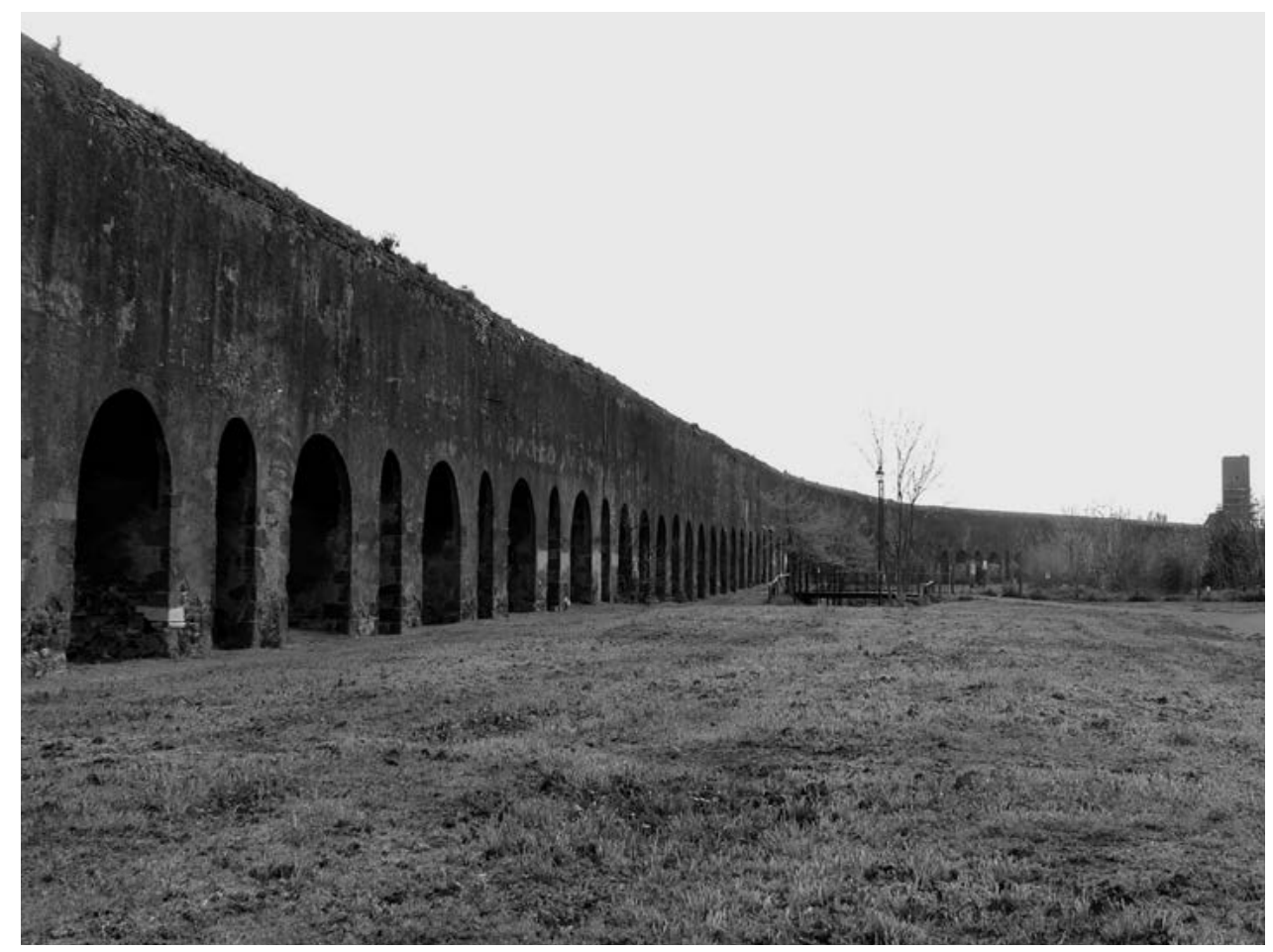

(A) Figura 4. Vista del acueducto de Claudio que caracteriza el paisaje de la Unidad de Libera

Fuente: foto del autor.

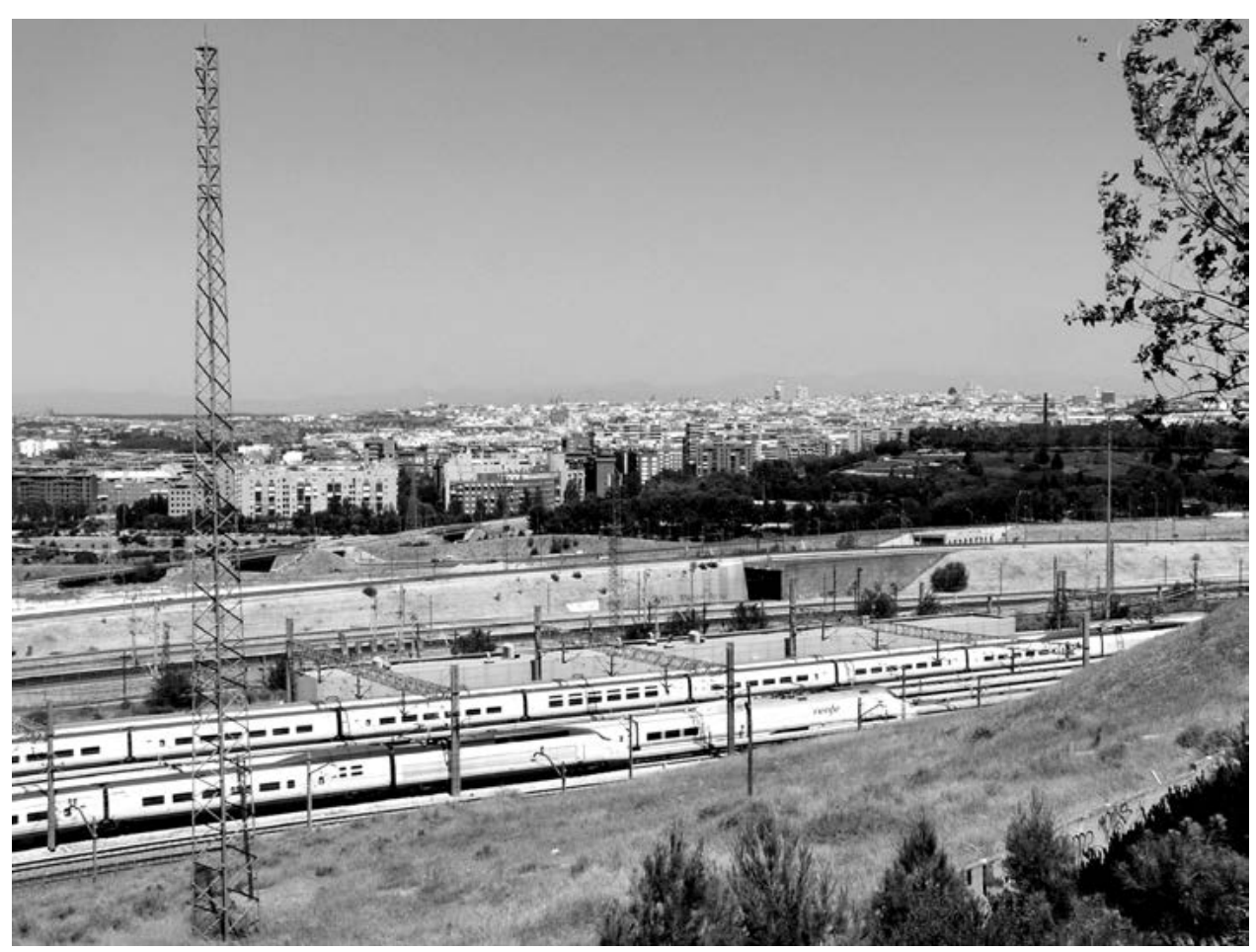

(A) Figura 5. Vista desde las "terrazas de Entrevías" Fuente: foto del autor.

1 El nombre Tuscolano viene de "Tuscolo", una de las montañas de origen volcánico, en este sector meridional del territorio de Roma. 


\section{Trazado}

En el Tuscolano y en Entrevías, el trazado que define la morfología de asentamiento determina la relación con el territorio y el paisaje.

El modelo de asentamiento propuesto en los dos conjuntos es de tipo geométrico, para conseguir simplicidad y poder dividir racionalmente la superficie; Hilberseimer asociaba estos asentamientos a los trazados de los campamentos nómadas, que tienen que ocupar y desocupar fácilmente un lugar. Acampar y desacampar se tiene que hacer con rapidez y orden. Según Hilberseimer, la tienda de campaña de los nómadas es el antecedente de la ciudad colonial y presenta de una manera sencilla sus principios reguladores; nuestros ensanches y nuestras ciudades de nueva planta son las ciudades coloniales de nuestra época (Hilberseimer, 1944). Otros ejemplos mostrados por el urbanista alemán en sus escritos son asentamientos de la Edad de Piedra, como lo de Castellazzo di Fontenallato en la Italia del norte, que presenta un trazado regular de insulae inscrito dentro de un perímetro constituido por terraplenes y excavaciones, con la finalidad de protección y defensa (Figura 6).

Este modelo de asentamiento en forma de enclave corresponde a la idea del Tuscolano, en donde el trazado regular de las viviendas está contenido dentro de un perímetro trapezoidal cerrado por un muro, siguiendo una geometría de tipo radial; todas las agrupaciones de viviendas y servicios de la Unidad del Tuscolano se distribuyen alrededor de la plaza jardín central, un espacio público que se organiza a partir de un trazado de caminos en forma de sol naciente. Entrevías, al contrario, no tiene limitaciones perimetrales, su sistema de agrupación es flexible, su geometría hace referencia al neoplasticismo y su crecimiento extensivo está limitado solamente por los accidentes geográficos, como en la antigua ciudad de Priene (Figura 7).

El espacio público de Entrevías se organiza a través del emplazamiento de una manzana libre y verde, cada cinco manzanas ocupadas por las agrupaciones de viviendas; la posición de esta "manzana verde" es variable, y genera paisajes diferentes en relación con la topografía y la distribución del construido (Figura 8).

\section{Calles y caminos}

Uno de los mecanismos creados por Hilberseimer y utilizado por Libera y Sáenz de Oíza es la calle cortada o cul-de-sac, instrumento que permite una ósmosis entre el tejido urbano y el paisaje, a través de un diseño urbano que favorece la circulación peatonal y que pone en relación de identidad la estructura de cada célula-hoja con la del conjunto-árbol, según una organización geométrica de tipo fractal.
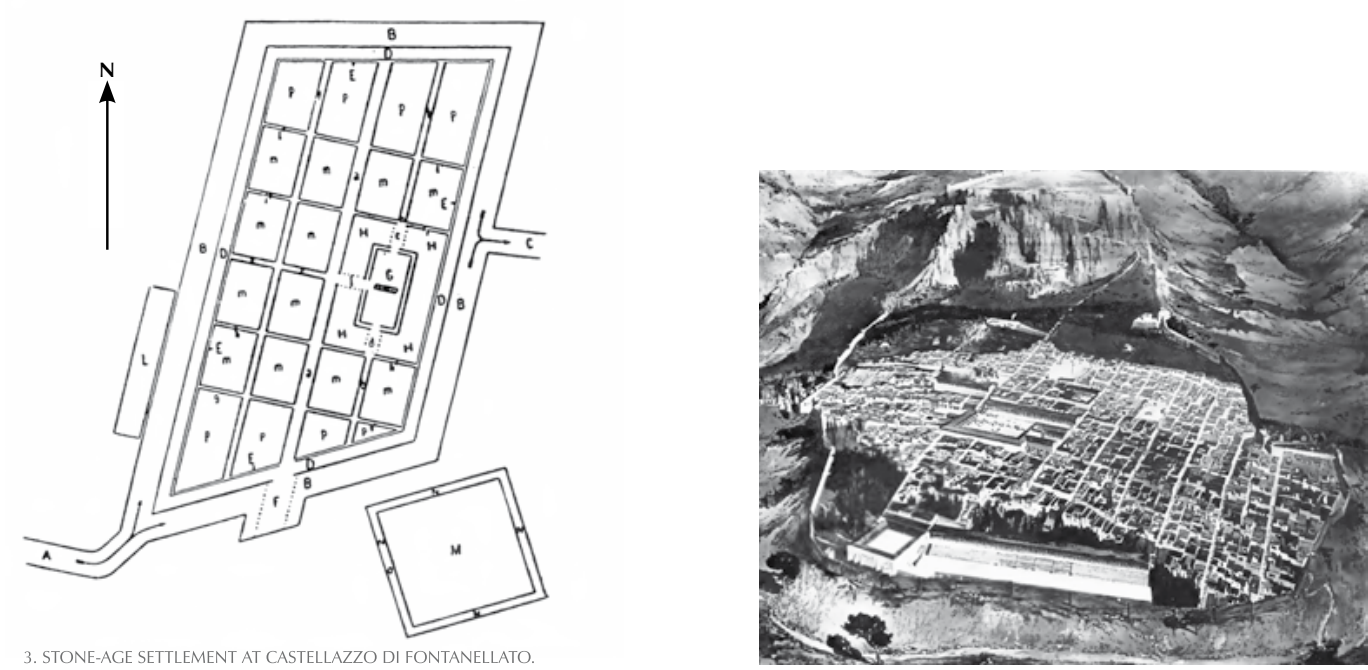

\& Figura 7. Reconstrucción de Priene, Asia Menor

Fuente: Hilberseimer (1944, p. 17).

(A) Figura 6. Asentamiento de la Edad de Piedra en Castellazzo di

Fontenallato, Italia

Fuente: Hilberseimer (1944, p. 21).
- Figura 8. Planimetría de la Unidad de Libera en comparación con la tercera fase de Entrevías de Sáenz de Oíza Fuente: elaboración propia.
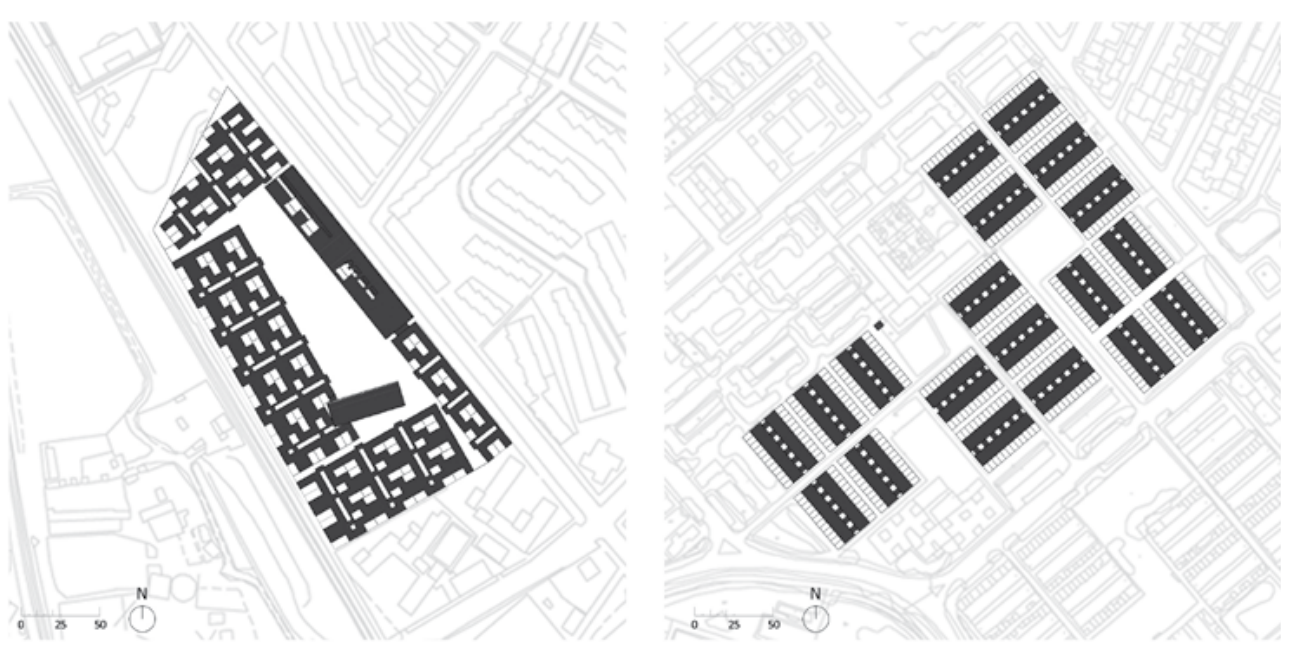

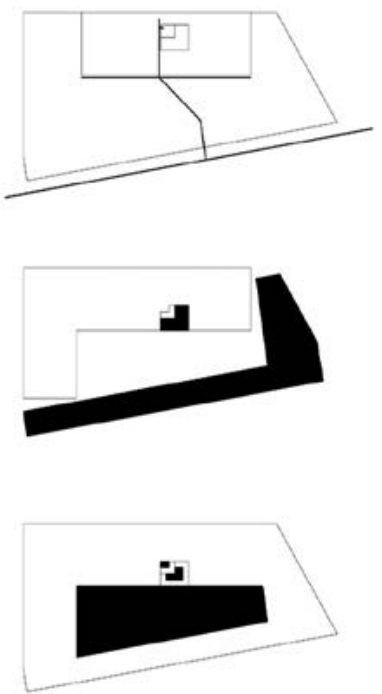

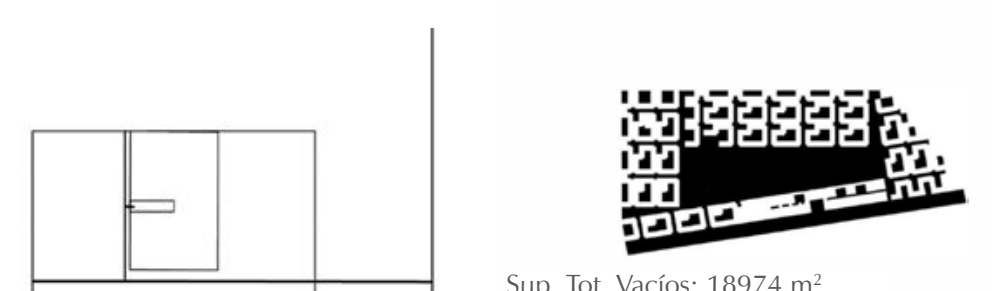

Sup. Tot. Vacíos: $18974 \mathrm{~m}^{2}$

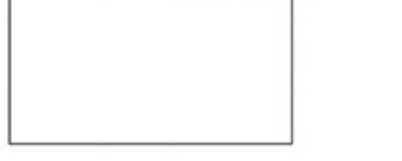

(A) Figura 9. Organización geométrica de tipo fractal en los dos conjuntos: "el árbol y la hoja"

Fuente: elaboración propia.

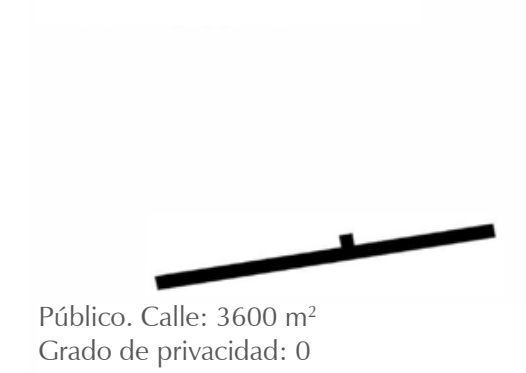

La metáfora del "árbol y de la hoja" presente en los croquis y apuntes de Libera y Sáenz de Oíza, tiene analogías con las teorías de Aldo van Eyck y su paralelismo entre casa/hoja y ciudad/árbol, y más en general con las reflexiones del Team $X$ sobre el importancia de la calle y su valor de estructura arquitectónico-social que fortalece las relaciones entre los habitantes (van Eyck, 2008) (Figura 9).

Sin embargo, en el Tuscolano y en Entrevías, como en las ciudades árabes, y de una forma distinta respecto al modelo de Hilberseimer, la calle hace parte de un sistema de vacíos que representa el negativo de lo construido; como señala Rafael Moneo citando a Leopoldo Torres Balbás (1954): "en las ciudades islámicas, son las casas las que al irse yuxtaponiendo determinan la traza de las calles, lo mismo de las que sirven de acceso a la vivienda que de las de tránsito" (1961, p. 17), mientras que en las ciudades occidentales las calles existen antes de las construcciones que se generan en los dos lados de las vías (Figura 10).

Distintos materiales caracterizan los recorridos en los dos barrios; sendas de tierra estabilizada y caminos de cemento en proximidad de las agrupaciones de viviendas, se trata del paisaje de una cultura nómada, con una espacialidad geométrica y centrípeta (Hilberseimer, 1944). El espacio del poblado de Entrevías, con los caminos ligeros trazados en sus terrenos áridos, es el paisaje desértico de los nómadas, un lugar vacío, un territorio "liso marcado por unos trazos que se borran y reaparecen con las idas y venidas" (Careri, 2002, p. 38). El recorrido del nómada se relaciona con la vida en una comunidad, personas que después de un largo viaje o de una migración, deciden detenerse para compartir sus experiencias, mientras que el recorrido del sedentario tiene que ver con la vida en la ciudad, la vida del ciudadano (p. 42).
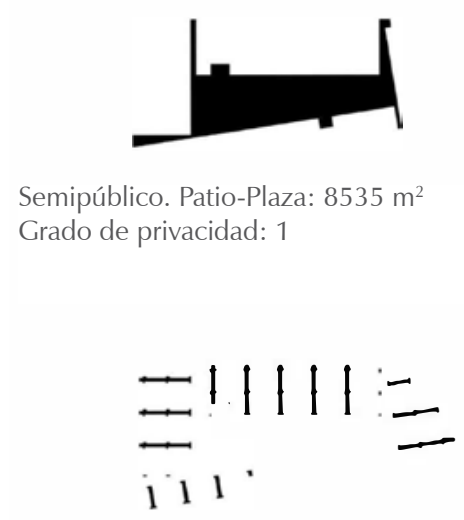

Semipúblico. Pasillos: $1758 \mathrm{~m}^{2}$ Grado de privacidad: 2

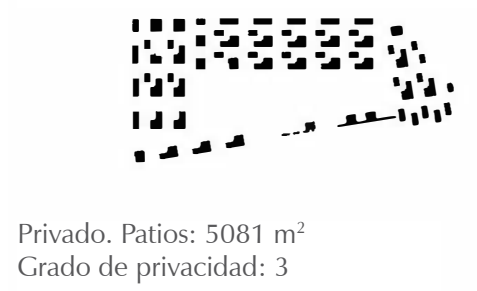

\section{Densidad}

El plan de emplazamiento general contenido en el proyecto de ejecución de las tres fases del poblado nos indica que el poblado dirigido de Entrevías siempre estuvo pensado para convivir con futuras edificaciones según una idea de densificación progresiva de los solares; también es cierto que las propuestas iniciales iban a favor de una ciudad-jardín de alta densidad. Corroboran esta hipótesis los datos sobre densidad media contenidos en la memoria del proyecto de ejecución que hablan de 240 habitantes por hectárea, contra los 600 de cada manzana que compone el poblado dirigido, los planos de jardinería hallados por el autor de este ensayo en el Archivo Regional de la Comunidad de Madrid en 2012, y la maqueta realizada en 1960, antes del desarrollo del plan de actuación, que fija la imagen de una ciudad que mira claramente a las investigaciones de Hilberseimer (Alvear y Alii, 1963). Este valor de densidad media más bajo es parecido a lo de la Unidad del Tuscolano que alcanza los 296 habitantes por hectárea, a los valores de Hilberseimer

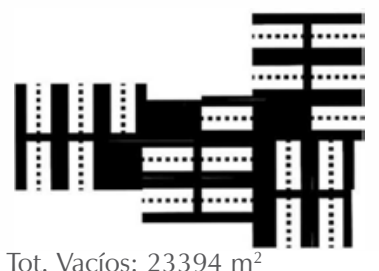

up. Tot. Vacíos: 23394 m²

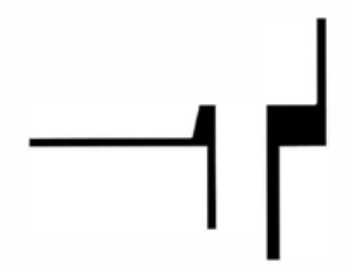

Público. Calles: 5564 m² Grado de privacidad: 0

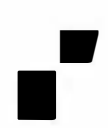

úblico. Plazas: $2264 \mathrm{~m}^{2}$ Grado de privacidad: 1

Público. Pasillos: 4483 m² Grado de privacidad: 2

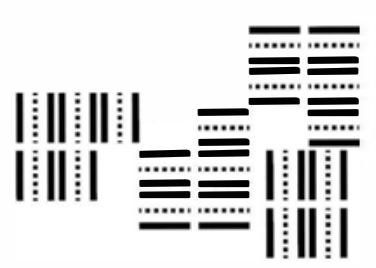

Privado. Patios: $11083 \mathrm{~m}^{2}$ Grado de privacidad: 3
A Figura 10. Ficha de análisis comparativo. El sistema de los vacíos: superficie pública y privada; calles, plazas y jardines

Fuente: elaboración propia. 
(7) Figura 11. Ficha de análisis comparativo: el sistema del paisaje, permeabilidad, relación áreas verdes/áreas construidas

Fuente: elaboración propia. que teoriza una densidad de 300 habitantes, y a los de la ciudad horizontal de Pagano que propone 250 habitantes. Se trata de valores medio-altos comparables a los de un centro urbano y que permiten una ciudad homogénea de densidad constante, con muchas áreas verdes.

Dos datos definen la calidad y cantidad del espacio verde que existe en los dos conjuntos. El dato de 0,61 se refiere al porcentaje de áreas verdes y espacios públicos en relación con la superficie construida en la Unidad de Libera, un valor muy superior al de 0,18 que expresa la misma relación en la unidad de Oíza. Más del doble es el dato en el Tuscolano si comparamos la superficie del espacio público y la de suelo urbanizado.

Si sumamos estas áreas públicas con las áreas verdes privadas, los patios y los patios-jardines en los dos conjuntos, la situación cambia y obtenemos un dato parecido para los dos casos: alrededor de 0,40, valor que expresa la relación entre las áreas verdes totales y la superficie de suelo urbanizado. Estos datos evidencian una misma "porosidad" en los dos proyectos, con una distinta relación público-privado, que en el Tuscolano es más equilibrada (Figura 11).

\section{Topografía y suelos}

Los datos sobre la topografía natural y artificial determinan dos naturalezas distintas. En Roma, un terreno con pendiente escasa, menor del $5 \%$, determina un conjunto en el cual la vivienda, las calles y los servicios se acomodan casi a la misma cota alrededor de la plaza-jardín central. El proyecto aparece como fuertemente arraigado en el suelo volcánico, nace de ello, y la elección del revestimiento en toba del muro perimetral es testimonio de este vínculo; un muro que parece surgir de la tierra, encerrando un fragmento de paisaje autóctono, el paisaje de la campiña romana.

El territorio donde surge Entrevías es un paisaje de terrazas artificiales, que establecen una mediación entre el suelo y la vivienda; las agrupaciones como volúmenes puros se asientan sobre las plataformas que solucionan pendientes hasta un $10 \%$ y parecen flotar sobre el paisaje de la meseta y las terrazas aluviales del Manzanares; se generan planos de la dimensión de una hectárea sobre los cuales se asientan las manzanas edificadas y las libres. En principio, estas terrazas estuvieron construidas exclusivamente por taludes de tierra compactada, en un segundo momento, pro-
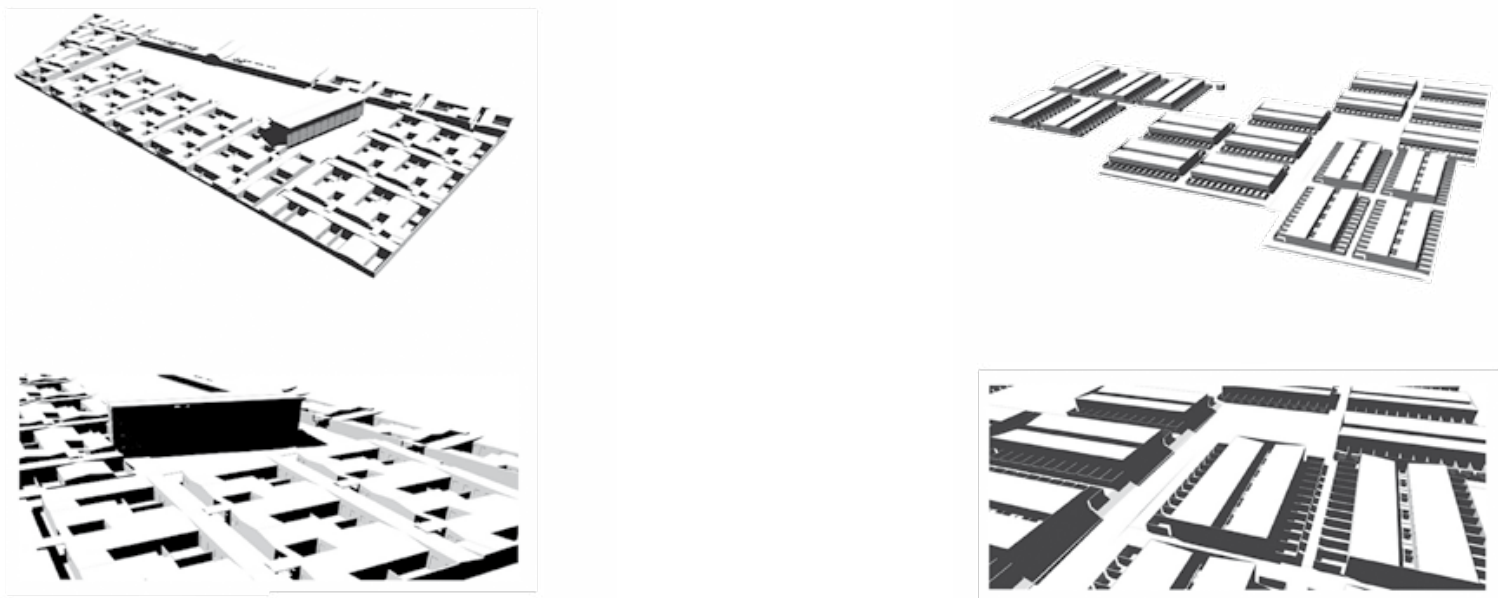

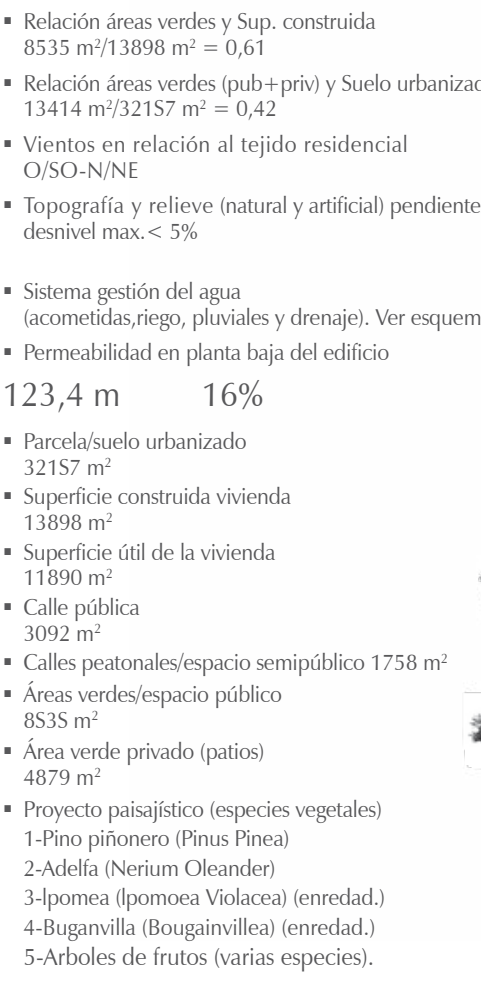
$\boldsymbol{\Lambda}_{0,61 \mathrm{~m}^{2} \mathrm{v} / \mathrm{m}^{2} \mathrm{c}}$

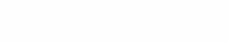

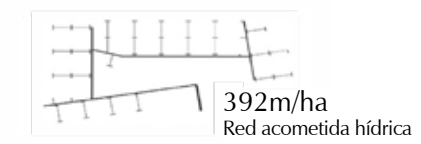

- Permeabilidad en planta baja del edificio
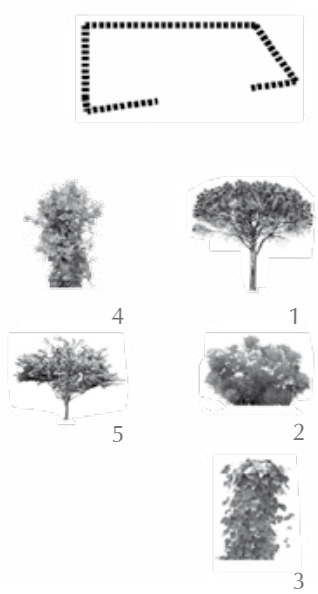

ROMA: Ficha escala "Unidad" no2. El sistema del Paisaje,

Permeabilidad, relación áreas verdes/construidas
- Relación Áreas verdes y Sup. construida

$5171 \mathrm{~m}^{2} / 27837 \mathrm{~m}^{2}=0,18$

- Relación áreas verdes (pub+ priv) y Suelo urbanizado $18057 \mathrm{~m}^{2} / 43804 \mathrm{~m}^{2}=0,41$

- Vientos en relación al tejido residencial

- Vientos

- Topografía y relieve (natural y artificial) pendientes: desnivel max. 10\%

plataformas artificiales desnivel entre 0,20 y 1,60 m

- Sistema gestión del agua

(acometidas, riego, pluviales y drenaje). Ver esquema

- Permeabilidad en planta baja del edificio

$508 \mathrm{~m} \quad 48 \%$

- Parcela/suelo urbanizado

$43804 \mathrm{~m}^{2}$

- Superficie construida vivienda

$27837 \mathrm{~m}^{2}$

- Superficie útil de la vivienda

$27123 \mathrm{~m}^{2}$

Calle pública vehicular

$6029 \mathrm{~m}^{2}$

- Calles peatonales/aceras/espacio semipúblico 5984 m²

- Áreas verdes/espacio público

- Areas ver $5171 \mathrm{~m}^{2}$

- Área verde privado (patios)

$12886 \mathrm{~m}^{2}$

- Proyecto paisajístico (especies vegetales más

representativas

1-Pino Carrasco (Pinus halepensis)

2-Piátano (Piatanus orienta lis)

3-Azahar de China (Pittosporum tobira)
- $\Delta \quad \Delta, 18 \mathrm{~m}^{2} \mathrm{v} / \mathrm{m}^{2} \mathrm{c}$
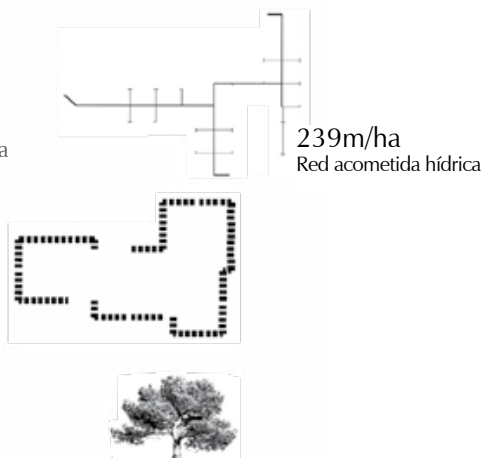

I

1
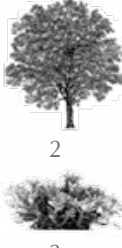

MADRID: Ficha escala "Unidad" o⒉ El sistema del Paisaje,

Permeabilidad, relación áreas verdes/construidas 
bablemente junto a los trabajos de densificación del barrio a partir de 1960, se completaron estos terraplenes añadiendo muros de contención en mampostería de granito de la cercana Sierra.

La obra de Oíza está influenciada por Oteiza, con el cual el arquitecto colaboró en algunos de sus más importantes proyectos, y se refleja en la búsqueda de una fuerte abstracción y contraste entre lleno y vacío, entre horizonte y volúmenes puros, aspectos presentes también en el proyecto de Entrevías, en donde es importante "el espacio no ocupado, como diría Oteiza, como vacío, como desahogo; pero este desahogo no es solo visual, está definido por el módulo, principio inadvertido del desarrollo" (Moneo, 1961, p. 11). Si las manzanas de Entrevías se asientan sobre el terreno con la mediación de las terrazas, la Unidad del Tuscolano, en cambio, parece surgir de la tierra sin soluciones de continuidad, su cubierta continua es una topografía artificial que parece fundirse con el paisaje natural, como en la escultura II grande Cretto de Alberto Burri: esta visión es posible desde las terrazas del edificio para solteros que se contrapone a la horizontalidad de las agrupaciones de casas co $\mathrm{n}$ patio.

La casa Malaparte en Capri y la Capilla en el camino de Santiago son, quizá, las obras que más sintetizan las ideas de los dos arquitectos respecto a la naturaleza y al paisaje. En la primera Libera construye un fuerte vínculo con el terreno rocoso del promontorio de la isla de Capri sobre el cual la casa se asienta casi enraizada en este; en la segunda, Sáenz de Oíza, junto a Oteiza proyecta un edificio ligero y abstracto que queda suspendido sobre los campos de Castilla, como los postes de alta tensión que Oíza sugería como referencia formal en la memoria del concurso (Sáenz, 2004). Dos imágenes que corresponden a dos miradas distintas, pero el mismo deseo de establecer una fuerte relación con el suelo y la topografía, una relación de tipo horizontal.

\section{Aire, sol y agua}

Los dos conjuntos se abren al sol y al viento, y la porosidad de las manzanas favorece esta permeabilidad climática; la orientación diagonal mejora las condiciones de confort en las vivien- das. Los vientos tienen direccionalidad prevalente de suroeste $y$, en menor medida, de noreste, sobre todo en invierno.

Ya hemos visto las diferentes condiciones climáticas de Roma y de Madrid: una mayor humedad del clima de la capital italiana, respecto a una condición continental y seca de la ciudad española. Estos aspectos se reflejan en la tipología de las agrupaciones en los dos casos de estudio: una manzana más compacta, que imita sus aberturas en Entrevías, respeto a la agrupación del Tuscolano, con más envolvente y huecos de fachada.

La investigación sobre el trazado de acometidas hídricas nos hace reflexionar sobre lo que definimos como criptosistema y que, junto al fenosistema, genera un geosistema, la suma de todos los elementos físicos, orgánicos e inorgánicos, visibles e invisibles. Los elementos "escondidos" de una urbanización, como las acometidas y el sistema de drenaje, hacen parte del criptosistema, e influyen sobre el proyecto paisajístico y ambiental en sus aspectos más técnicos y geométricos (Fariña, 1998, p. 260). Los 239 metros por hectáreas de red de acometida hídrica calculados en la Unidad de Entrevías confirman unas de las ideas a la base del planteamiento de Sáenz de Oíza: el máximo ahorro en instalaciones; esta cantidad es baja también en Roma (249 m), debido a la compactibilidad del conjunto. Como intenta demostrar Libera a través de su "vivienda-manifiesto", se puede lograr rentabilidad constructiva, también en un conjunto de una sola planta (Libera, 1955).

\section{Vegetación}

En la elección de las especies vegetales que caracterizan los espacios públicos de las unidades, los arquitectos optan por un "paisaje autóctono", el paisaje del mediterráneo que caracteriza las ciudades de Madrid y Roma. El descubrimiento entre los documentos del proyecto de ejecución de Entrevías, del proyecto de jardinería y paisaje (1958), ha permitido una comparación más efectiva con el proyecto del Tuscolano. La presencia de los pinos es lo que caracteriza los dos hábitats y contribuye a definir esta idea de paisaje lugareño y espontáneo. Se trata del pino piñonero (Pinus pinea), el típico pino de la campiña romana,

\footnotetext{
$>$ Figura 12. Vista de la plaza-jardín pública en la Unidad de Roma

Fuente: elaboración propia.

$\rightarrow$ Figura 13. Vista de uno de los espacios verdes en la segunda fase del poblado dirigido de Entrevías

Fuente: elaboración propia.
}
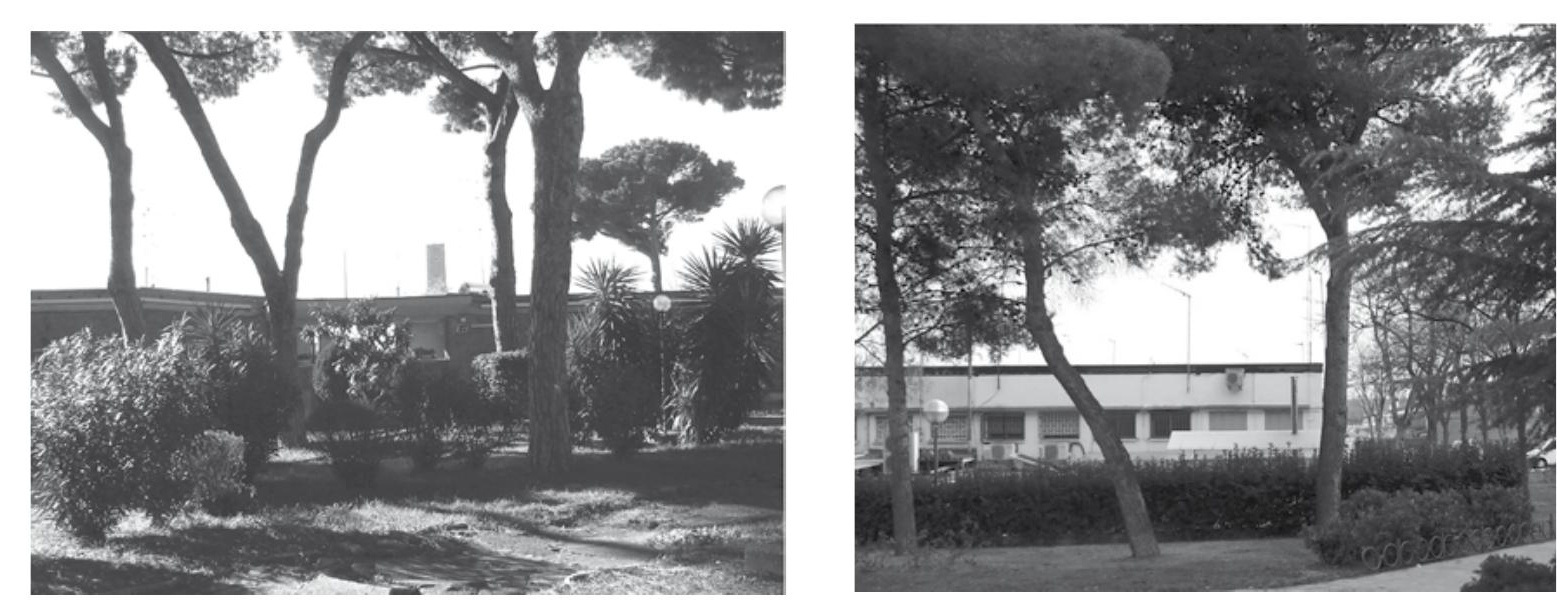
parte de la imagen monumental de la Capital italiana. En Entrevías se utiliza el pino Carrasco (Pinus halepensis), que por sus características y tamaño, mejor se adapta al clima árido de la capital española, presente en todos los parques urbanos de esta ciudad (Figuras 12 y 13).

En el Tuscolano, el tratamiento paisajístico queda limitado a la plaza-jardín y a las calles de acceso a las viviendas, en donde unas plantas enredaderas decoran los muros de las casas. En el espacio público central, unos arbustos de adelfa (Nerium oleander) delimitan el camino peatonal que desde la entrada a la unidad lleva al bloque de vivienda para solteros, uno de los caminos radiales de distribución a las distintas agrupaciones. Unas pequeñas plazuelitas con bancas revestidas en toba, una por cada camino, completan el diseño.

En Entrevías, el diseño del paisaje no se limita a las plazas públicas y a las calles peatonales que distribuyen las viviendas; dos tipologías de arbolado definen las áreas libres que separan las unidades habitacionales de las calles de tránsito vehicular: se trata de hileras de plátanos, o franjas tupidas de chopos (Populus nigra piramidalis), plátanos (Platanus orientalis) y pinos (Pinus halepensis). Estas franjas verdes muy densas tienen una referencia con el paisajismo planteado por Hilberseimer y Mies junto con Alfred Caldwell, la idea de fortalecer a través de masas tupidas de vegetación la imagen de una ciudad que se funde con el paisaje y se esconde en la naturaleza.
En las plazas públicas se proponen plátanos que construyen masas de geometría ortogonal o hileras para delimitar y proteger pequeñas plazas o áreas de juegos para niños; se trata también de una técnica presente en los proyectos paisajísticos de Caldwell, que utiliza los árboles para fortalecer la percepción de los espacios vacíos (Llobet i Ribeiro, 2008).

En la Unidad del Tuscolano se desarrolla una imagen paisajística diferente que, sin embargo, fortalece como en Entrevías una dimensión autóctona y local, un proyecto que se vincula con el territorio de Roma, con el paisaje de la campiña, su geología, hidrología y vegetación, con referencia a la investigación desarrollada por Libera en sus proyectos de anteguerra, como el "Lungo mare de Castelfusano", y las propuestas de Ponti y Rudofsky sobre la casa mediterránea, sobre todo algunos proyectos que estos dos autores desarrollan para asentamientos turísticos en la isla de Capri o en Dalmacia a partir de los años cuarenta (Ponti, 1941). En algunos dibujos en plantas publicados en estos años por Ponti, las casas se convierten en "ruinas"; las viviendas se construyen a partir de muros espesos que delimitan espacios abiertos en los cuales la vegetación, casi siempre de pinos y arbustos, penetra transformando el espacio doméstico en un jardín. De la misma forma, se perciben en el Tuscolano los pinos del espacio público central, que construyen un paisaje que es imposible imaginar separadamente de lo construido, una figura en la cual el muro exterior de toba define la imagen de la Unidad junto a los altos árboles.

En el borde de las calles de acceso a las viviendas de los dos conjuntos, una vegetación arbustiva de enredaderas enriquece estos espacios. Los muros que separan los patios que dan a las calles son diafragmas permeables y filtran hacia el espacio público lo verde de los jardines privados.

Los patios permiten también el vínculo entre los habitantes y la tierra en el contexto urbano: tanto Libera como Oíza piensan en el origen campesino de los futuros habitantes. Estos espacios verdes se transforman así en habitaciones al aire libre, donde es posible desarrollar también actividades productivas y creativas, facilitando fenómenos de autogestión y participación, y fomentando el cuidado de los espacios comunes (Figura 14).

\section{Conclusiones}

Los dos casos de estudio plantean una relectura de las teorías de Hilberseimer y su aplicación en contextos territoriales específicos: Roma y Madrid. El modelo abstracto e ideal del urbanista alemán, pensado por el planeamiento de las metrópolis de Estados Unidos, se convierte en un fragmento de ciudad real, en la Europa de la posguerra, en contextos marcados por una difícil situación económica. En este pasaje de lo 
ideal a lo efectivo Libera y Sáenz de Oíza proponen un paisaje construido autóctono utilizando la matriz común de la cultura mediterránea. Los dos proyectos se sirven del análisis del territorio y de sus estructuras ambientales como punto de partida para el desarrollo de un hábitat que integra vivienda y paisaje, natural y artificial.

En el estudio comparativo hemos podido reconocer estrategias comunes en el proceso de diseño. Primero que todo la importancia del trazado que pone en relación la vivienda con caminos, calles y espacios verdes públicos, un trazado que tiene múltiples raíces culturales así como lo planteado en los escritos de Hilberseimer: el campamento nómada, la ciudad árabe y la polis griega.

Otro aspecto importante son los elementos naturales que llegan a ser herramientas de proyecto: el sol, el aire, el agua; se busca el confort climático y ambiental, y también la eficiencia en la distribución de drenaje y acometidas a través de una correcta orientación y agrupación de las unidades. Se trabaja sobre la porosidad de lo construido llegando en los dos casos de estudio al mismo porcentaje del $40 \%$ de área libre en relación con el suelo urbanizado; este valor está fuertemente relacionado con el proyecto de jardinería que en los dos conjuntos dispone las masas arbóreas para construir arquitectónicamente el espacio vacío.

Sobre todo, hay que subrayar que el Tuscolano y Entrevías pueden entenderse como dos topografías que se adaptan a las distintas condiciones geológicas, orográficas y urbanas de Roma y Madrid: una relación directa en el caso de Roma, y filtrada a través de plataformas artificiales en el conjunto de Madrid.

La fuerte conexión que los dos conjuntos establecen con el suelo es probablemente el aspecto que determinó el escaso éxito del modelo del hábitat horizontal en Italia y en España, países que en todo el siglo XX sufrieron más que otros países europeos las presiones de la especulación de los capitales privados (Benevolo, 1993). Como lo planteó Giuseppe Pagano en sus investigaciones sobre la "ciudad horizontal" para la ciudad de Milán, estas hipótesis hubieran necesitado una nueva configuración del régimen de suelos y una intervención pública más eficaz y duradera. No fueron suficientes las densidades medio-altas planteadas, parecidas a otros barrios en altura realizados en estos años; estos modelos no tuvieron éxito en los dos países, que por condiciones climáticas y culturales hubieran sido ideales para el desarrollo de esta tipología de hábitat;es una paradoja que, en cambio, este arquetipo se hubiera difundido a partir de los años sesenta sobre todo en los países del norte de Europa.

El Tuscolano y Entrevías representan un paradigma de sostenibilidad en la vivienda colectiva, todavía actual y válido, sobre todo en contextos menos desarrollados como los de Latinoamérica, que podrían invertir con más eficacia en estrategias de diseño que no buscan soluciones tecnológicas, sino que proponen una diferente aproximación al proyecto de arquitectura. Se trata de una nueva sensibilidad que, según lo planteado por Juan Herreros (2006), se basa en el descubrimiento "de que hay un mundo intermedio formado por el aire, la humedad, el polen, el paso de las estaciones, el crecimiento de los organismos... que deben ser considerados auténticos materiales técnicos de construcción". A partir de estas nuevas herramientas podemos definir un proyecto de hábitat que considera las estructuras arquitectónicas en fuerte relación con las estructuras ambientales y sociales, que mira al contexto teniendo en cuenta las diferentes escalas, desde la célula hasta el territorio, y logra transformar el paisaje físico en un paisaje cultural.

\section{Referencias}

Alvear, J. y Alii, E. (1963). Barrio de Entrevías. Arquitectura (58), 2-29.

Archivo Regional de la Comunidad de Madrid (1958). Proyecto de jardineria y zonas de juego en el poblado dirigido, tercera fase, de Entrevías. Madrid: Archivo Regional de la Comunidad de Madrid (ARCM).

Baldellou, M. Á. (1995). Editorial. Arquitectura (301), 7 .

Benevolo, L. (1993). La città nella storia d'Europa. Bari: Laterza.

Benevolo, L. y Albrecht, B. (2002). Le origini dell'architettura. Roma: Laterza.

Careri, F. (2002). Walkscapes: el andar como práctica estética. Barcelona: Gustavo Gili.

Colella, F. (2015). El paisaje de Entrevías. Estructuras ambientales y territoriales en el poblado dirigido de Francisco J. Sáenz de Oiza. BitáCora Arquitectura, (31), 46-55. Recuperado de http://www.revistas.unam.mx/ index.php/bitacora/article/view/56160
Eyck van, A. (2008). Writings. The child, the city and the artist. En Ligtelijn, V. y Strauven, F. (eds.). Collected Articles and other writings 1947-1998. Amsterdam: Sun Publishers.

Fariña Tojo, J. (1998). La ciudad y el medio natural. Tres Cantos, Madrid: Akal Ediciones.

Herreros, J. (2006). Transferencias por un pensar técnico. Recuperado de http://habitat. aq.upm.es/boletin/n38/ajher.html

Hilberseimer, L. (1944). The New City. Principles of Planning. Chicago: Paul Theobald.

Libera, A. (1955). Il quartiere Tuscolano a Roma. Comunitá (31), 46-49.

Llobet i Ribeiro, X. (2008). Hilberseimer y Mies: la metrópoli como ciudad jardin. Barcelona: Fundación Caja de Arquitectos.

Moneo, R. (1961). El poblado dirigido de Entrevías. Hogar y Arquitectura (34), 3-23.

Pagano, G., Diotallevi, I. y Marescotti, F. (1940). Quartiere della cittá orizzontale. Casabella Costruzioni (148), 14-21.
Ponti, G. (1941). Turismo mediterraneo italiano y turismo ideale nella Dalmazia. Stile (9), 15-22.

Sáenz de Oíza, F. J., Sierra Nava, M. y Alvear Criado, J. (1956). Proyecto de ejecución, Memoria. Poblado dirigido de Entrevías, primera fase de 770 viiviendas y edificios públicos. Madrid: s. e.

Sáenz Guerra, F. J. (2004). Francisco Javier Sáenz de Oiza, José Luis Romany, Jorge Oteiza: una capilla en el camino de Santiago = A chapel on St. James Way, 1954. Madrid: Rueda.

Torres Balbás, L., Cervera Vera, L., Chueca Goitia, F. y Bidagor Lasarte, P. (1954). Resumen histórico del urbanismo en España. Madrid: Instituto de Estudios de Administración Local.

Zanuso, M. (1955). Untá dàbitazione orizzontale nel quartiere Tuscolano a Roma. CasabeIla (207), 30-37. 
La postulación de un artículo a la Revista de Arquitectura indica que- el o los autores certifican que conocen y aceptan la política editorial, para lo cual firmarán en original y remitirán el formato RevArq FP00 Carta de originalidad.

La Revista de Arquitectura maneja una política de Autoarchivo VERDE, según las directrices de SHERPA/RoMEO, por lo cual el autor puede:

- Pre-print del autor: Archivar la versión pre-print (la versión previa a la revisión por pares)

- Post-print del autor: Archivar la versión post-print (la versión final posterior a la revisión por pares

- Versión de editor/PDF: Archivar la versión del editor - PDF/HTML/XLM en la maqueta de la Revista de Arquitectura.

El Autoarchivo se debe hacer respetando la licencia de acceso abierto, la integridad y la imagen de la Revista de Arquitectura, también se recomienda incluir la referencia, el vínculo electrónico y el DOI.

El autor o los autores son los titulares del Copyright (c) del texto publicado y la Editorial de la Revista de Arquitectura solicita la firma de una autorización de reproducción del artículo (RevArq FP03 Autorización reproducción), la cual se acoge a la licencia CC, donde se expresa el derecho de primera publicación de la obra.

La Revista de Arquitectura se guía por las normas internacionales sobre propiedad intelectual y derechos de autor, y de manera particular el artículo 58 de la Constitución Política de Colombia, la Ley 23 de 1982 y el Acuerdo 172 del 30 de septiembre de 2010 (Reglamento de propiedad intelectual de la Universidad Católica de Colombia).

Para efectos de autoría y coautoría de artículos se diferencian dos tipos: "obra en colaboración" y "obra colectiva". La primera es aquella cuya autoría corresponde a todos los participantes al ser fruto de su trabajo conjunto. En este caso, quien actúa como responsable y persona de contacto debe asegurar que quienes firman como autores han revisado y aprobado la versión final, y dan consentimiento para su divulgación. La obra colectiva es aquella en la que, aunque participan diversos colaboradores, hay un autor que toma la iniciativa, la coordinación y realización de dicha obra. En estos casos, la autoría corresponderá a dicha persona (salvo pacto en contrario) y será suficiente únicamente con su autorización de divulgación.

El número de autores por artículo debe estar justificado por el tema, la complejidad y la extensión, y no deberá ser superior a la media de la disciplina, por lo cual se recomienda que no sea mayor de cinco. El orden en que se enuncien corresponderá a los aportes de cada uno a la construcción del texto, se debe evitar la autoría ficticia o regalada. Si se incluyen más personas que trabajaron en la investigación se sugiere que sea en calidad de colaboradores o como parte de los agradecimientos. La Revista de Arquitectura respetará el número y el orden en que figuren en el original remitido. Si los autores consideran necesario, al final del artículo pueden incluir una breve descripción de los aportes individuales de cada uno de firmantes.

La comunicación se establece con uno de los autores, quien a su vez será el responsable de informar a los demás autores de las notificaciones emitidas por la Revista de Arquitectura.

En virtud de mantener el equilibro de las secciones y las mismas oportunidades para todos los participantes, un mismo autor puede postular dos o más artículos de manera simultánea; si la decisión editorial es favorable y los artículos son aceptados, su publicación se realizará en números diferentes.

\section{A Acceso abierto}

La Revista de Arquitectura, en su misión de divulgar la investigación y apoyar el conocimiento y la discusión en los campos de interés, proporciona acceso abierto, inmediato e irrestricto a su contenido de manera gratuita mediante la distribución de ejemplares impresos y digitales. Los interesados pueden leer, descargar, guardar, copiar y distribuir, imprimir, usar, buscar o referenciar e texto completo o parcial de los artículos o la totalidad de la Revista de Arquitectura.

\section{(c) (1) (3)}

Esta revista se acoge a la licencia Creative Commons (CC BYNC de Atribución - No comercial 4.0 Internacional): "Esta licencia permite a otros entremezclar, ajustar y construir a partir de su obra con fines no comerciales, y aunque en sus nuevas creaciones deban reconocerle su autoría y no puedan ser utilizadas de manera comercial, no tienen que estar bajo una licencia con los mismos términos".

La Revista de Arquitectura es divulgada en centros y grupos de investigación, en bibliotecas y universidades, y en las principales facultades de Arquitectura, mediante acceso abierto a la versión digital y suscripción anual al ejemplar impreso o por medio de canje, este último se formaliza mediante el formato RevArq FP20 Canjes.

Para aumentar su visibilidad y el impacto de los artículos, se envían a bases de datos y sistemas de indexación y resumen (SIR) y, asimismo, pueden ser consultados y descargados en la página web de la revista.

La Revista de Arquitectura no maneja cobros, tarifas o tasas de publicación de artículo (Article Processing Charge-APC), o por el sometimiento de textos a la publicación.

\section{(1)Ética y buenas prácticas}

La Revista de Arquitectura se compromete a cumplir y respetar las normas éticas en todas las etapas del proceso de publicación. Los autores de los artículos publicados darán cumplimiento a los principios éticos contenidos en las diferentes declaraciones y legislaciones sobre propiedad intelectual y derechos de autor específicos del país donde se realizó la investigación. En consecuencia, los autores de los artículos postulados y aceptados para publicar, que presentan resultados de investigación, deben firmar la declaración de originalidad (formato RevArq FP00 Carta de originalidad).

La Revista de Arquitectura reconoce y adopta los principios de transparencia y buenas prácticas descritos por COPE, "Principles of Transparency and Best Practice in Scholarly Publishing" (2015).

El equipo editorial tiene la obligación de guardar la confidencialidad acerca de los artículos recibidos, y abstenerse de usar en sus propias investigaciones datos, argumentos o interpretaciones hasta tanto el artículo no sea publicado. También debe ser imparcial y gestionar los artículos de manera adecuada y en los plazos establecidos. La selección de revisores se hará con objetividad y estos deberán responder a la temática del artículo.

El editor, los autores y los revisores deben seguir las normas éticas internacionales definidas por el Committee on Publication Ethics (COPE), con el fin de evitar casos de:

- Fabricación, falsificación u omisión de datos.

- Plagio y autoplagio.

- Publicación redundante, duplicada o fragmentada.

- Omisión de referencias a las fuentes consultadas.

- Utilización de contenidos sin permiso o sin justificación.

- Apropiación individual de autoría colectiva.

- Cambios de autoría.

- Conflicto de interés (CDI) no revelado o declarado.

- Otras que pudieran surgir en el proceso de investigación y publicación. La fabricación de resultados se genera al mostrar datos inventados por los autores; la falsificación resulta cuando los datos son manipulados y cambiados a capricho de los autores; la omisión se origina cuando los autores ocultan deliberadamente un hecho o dato. El plagio se da cuando un autor presenta como ideas propias datos creados por otros. Los casos de plagio son los siguientes: copia directa de un texto sin entrecomillar o citar la fuente, modificación de algunas palabras del texto, paráfrasis y falta de agradecimientos; el autoplagio se da cuando el mismo autor reutiliza material propio que ya fue publicado, pero sin indicar la referencia al trabajo anterior. La revista se apoya en herramientas digitales que detectan cualquiera de estos casos en los artículos postulados, y es labor de los editores y revisores velar por la originalidad y fidelidad en la citación. La publicación redundante o duplicada se refiere a la copia total, parcial o alterada de un trabajo ya publicado por el mismo autor

En caso de sospechar de alguna mala conducta se recomienda seguir los diagramas de flujo elaborados por COPE (2008), con el fin de determinar las acciones correspondientes.

La Revista de Arquitectura se reserva el derecho de retractación de publicación de aquellos artículos que, posterior a su publicación, se demuestre que presentan errores de buena fe, o cometieron fraudes o malas prácticas científicas. Esta decisión se apoyará en "Retraction Guidelines" (COPE, 2009). Si el error es menor, este se podrá rectificar mediante una nota editorial de corrección o una fe de erratas. Los autores también tienen la posibilidad de solicitar la retractación de publicación cuando descubran que su trabajo presenta errores graves. En todos los casos se conservará la versión electrónica y se harán las advertencias de forma clara e inequívoca.

\section{(A) Privacidad y manejo de la información.} Habeas Data

Para dar cumplimiento a lo previsto en el artículo 10 del Decreto 1377 de 2013, reglamentario de la Ley 1581 de 2012, y según el Acuerdo 002 del 4 de septiembre de 2013 de la Universidad Católica de Colombia, "por el cual se aprueba el manual de políticas de tratamiento de datos personales":

La Universidad Católica de Colombia, considerada como responsable o encargada del tratamiento de datos personales, manifiesta que los datos personales de los autores, integrantes de los comités y pares revisores, se encuentran incluidos en nuestras bases de datos; por lo anterior, y en cumplimiento de las disposiciones legales vigentes, la Universidad solicitará siempre su autorización, para que en desarrollo de sus funciones propias como Institución de Educación Superior, en especial las relacionadas con la docencia, la extensión y la investigación, la Universidad Católica de Colombia pueda recolectar, recaudar, almacenar, usar, circular, suprimir, procesar, intercambiar, compilar, dar tratamiento, actualizar, transmitir o transferir a terceros países y disponer de los datos que le han suministrado y que han sido incorporados en las bases de datos de todo tipo que reposan en la Universidad.

La Universidad Católica de Colombia queda autorizada, de manera expresa e inequívoca, en los términos señalados por el Decreto 1377 de 2013, para mantener y manejar la información de nuestros colaboradores (autores, integrantes de los diferentes comités y pares revisores); así mismo, los colaboradores podrán ejercer sus derechos a conocer, actualizar, rectificar y suprimir sus datos personales, para lo cual se han dispuesto las siguientes cuentas de correo electrónico: 
La Revista de Arquitectura recibe artículos de manera permanente. Los artículos se procesan a medida que se postulan, dependiendo el flujo editorial de cada sección.

El idioma principal es el español, y como opcionales están definidos el inglés, el portugués y el francés; los textos pueden ser escritos y presentados en cualquiera de estos.

Los artículos postulados deben corresponder a las categorías universalmente aceptadas como producto de investigación, ser originales e inéditos y sus contenidos responder a criterios de precisión, claridad y brevedad.

Como punto de referencia se pueden tomar las tipologías y definiciones del Índice Bibliográfico Nacional, Publindex (2010) que se describen la continuación:

1. Artículo de revisión: documento resultado de una investigación terminada donde se analizan, sistematizan e integran los resultados de investigaciones publicadas o no publicadas, sobre un campo en ciencia o tecnología, con el fin de dar cuenta de los avances y las tendencias de desarrollo. Se caracteriza por presentar una cuidadosa revisión bibliográfica de por lo menos 50 referencias.
2. Artículo de investigación científica y tecnológica: documento que presenta, de manera detallada, los resultados originales de proyectos terminados de investigación. La estructura generalmente utilizada contiene cuatro apartes importantes: introducción, metodología, resultados y conclusiones.

3. Artículo de reflexión: documento que presenta resultados de investigación terminada desde una perspectiva analítica, interpretativa o crítica del autor, sobre un tema específico, recurriendo a fuentes originales.

En todos los casos se debe presentar la información suficiente para que cualquier investigador pueda reproducir la investigación y confirmar o refutar las interpretaciones defendidas.

También se pueden presentar otro tipo de documentos diferentes a los anteriormente descritos, como pueden ser: artículo corto, reporte de caso, revisión de tema, documento resultado de la revisión crítica de la literatura sobre un tema en particular, cartas al editor, traducción, documento de reflexión no derivado de investigación, reseña bibliográfica, así como proyectos de arquitectura o urbanismo, entre otros

\section{A Instrucciones para postular artículos}

Postular el artículo en la página web de la Revista de Arquitectura y adjuntar comunicación escrita dirigida al editor RevArq_FP00 Carta de originalidad (debidamente firmada por todos los autores en original); de igual manera, se debe diligenciar el formato de hoja de vida RevArq FP01 Hoja de Vida (una por cada autor).

En la comunicación escrita el autor expresa que conoce y acepta la política editorial de la Revista de Arquitectura, que el artículo no está postulado para publicación simultáneamente en otras revistas u órganos editoriales y que no existe conflicto de intereses (ver modelo RevArq FP06 CDI) y que, de ser aceptado, concederá permiso de primera publicación, no exclusiva a nombre de la Universidad Católica de Colombia como editora de la revista.

Los artículos deben tener en cuenta las siguientes recomendaciones:

- En la primera página del documento se debe incluir:

Título: no exceder 15 palabras.

Subtítulo: opcional, complementa el título o indica las principales subdivisiones del texto.

Nombre del autor o autores: nombres y apellidos completos o según modelo de citación adoptado por el autor para la normalización de los nombres del investigador. Como nota al pie (máximo 150 palabras): formación académica, experiencia profesional e investigativa, vinculación laboral, código ORCID, premios o reconocimientos, publicaciones representativas e información de contacto, correo electrónico.

Filiación institucional: debajo del nombre se debe declarar la institución en la cual se desarrolló el producto, de la cual recibió apoyo o aquella que respalda el trabajo investigativo.

Resumen: debe ser analítico, se redacta en un solo párrafo, da cuenta del tema, el objetivo, la metodología, los resultados y las conclusiones; no debe exceder las 150 palabras.

Palabras clave: cinco palabras o grupo de palabras, ordenadas alfabéticamente y que no se encuentren en el título o subtítulo; estas sirven para clasificar temáticamente al artículo. Se recomienda emplear principalmente palabras definidas en el tesauro de la Unesco (http:// databases.unesco.org/thessp/), en el tesauro de Arte \& Arquitectura (C (www.aatespanol.cl), o Vitruvio (http://vocabularyserver.com/vitruvio/)

También se recomienda incluir título, resumen y palabras clave en segundo idioma.

\section{- La segunda página y siguientes deben tener en cuenta:}

El cuerpo del artículo generalmente se divide en: Introducción, Metodología, Desarrollo, Resultados y Discusión de resultados; posteriormente se presentan las Conclusiones, y luego las Referencias bibliográficas y los Anexos (método IMRYD). Las tablas y figuras se deben incorporar en el texto.

Descripción del proyecto de investigación: en la introducción se debe describir el tipo de artículo y brevemente el marco investigativo del cual es resultado y diligenciar el formato (RevArq FP02 Info Proyectos de Investigación).

TEXTO: todas las páginas deben venir numeradas y con el título de artículo en la parte superior de la página. Márgenes de $3 \mathrm{~cm}$ por todos los lados, interlineado doble, fuente Arial o Times New Roman de 12 puntos, texto justificado (Ver plantilla para presentación de artículos). La extensión de los artículos debe ser de alrededor de 5.000 palabras ( \pm 20 páginas, incluyendo gráficos, tablas, referencias, etc.); como mínimo 3.500 y máximo 8.000 palabras. Se debe seguir el estilo vigente y recomendado en el Manual para Publicación de la American Psychological Association (APA). (Para mayor información véase http://www.apastyle.org/)
Citas y notas al pie: las notas aclaratorias o notas al pie no deben exceder cinco líneas o 40 palabras, de lo contrario estas deben ser incorporadas al texto general. Las citas pueden ser:

Corta: (con menos de 40 palabras) se incorporan al texto y pueden ser: textuales (se encierran entre dobles comillas), parafraseo o resumen (se escriben en palabras del autor dentro del texto).

Cita textual extensa: (mayor de 40 palabras) debe ser dispuesta en un renglón y un bloque independiente con sangrías y omitiendo las comillas, no olvidar en ningún caso la referencia del autor (Apellido, año, página).

Referencias: como modelo para la construcción de referencias se emplea el estilo recomendado en el Manual para Publicación de la American Psychological Association (APA) (http://www.apastyle.org/).

Siglas: en caso de emplear siglas en el texto, las figuras o las tablas, se debe proporcionar la equivalencia completa la primera vez que se empleen y encerrarlas entre paréntesis. En el caso de citar personajes reconocidos se deben colocar nombres o apellidos completos, nunca emplear abreviaturas.

Figuras y tablas: las figuras (gráficos, diagramas, ilustraciones, planos, mapas o fotografías) y las tablas deben ir numeradas y contener título o leyenda explicativa relacionada con el tema del artículo, que no exceda las 15 palabras (Figura 1. xxxxx, Tabla 1. xxxx, etc.) y la procedencia (fuente: autor o fuente, año, página). Estas se deben referenciar en el texto de forma directa o entre paréntesis; se recomienda hacerlo con referencias cruzadas.

También se deben entregar en medio digital, independiente del texto, en formatos editables o abiertos. La marcación de los archivos debe corresponder a la incluida en el texto. Según la extensión del artículo se deben incluir de 5 a 10 gráficos. Ver guía para la búsqueda de imágenes de dominio público o bajo licencias Creative Commons (CC).

El autor es el responsable de adquirir los derechos o las autorizaciones de reproducción a que haya lugar para imágenes o gráficos tomados de otras fuentes, así como de entrevistas o material generado por colaboradores diferentes a los autores; de igual manera, se debe garantizar la protección de datos e identidades para los casos que sea necesario.

FOTOGRAFíA: pueden ser entregadas en original para ser digitalizadas, de lo contrario se deben digitaliza r con una resolución igual o superior a 300 dpi para imágenes a color y 600 para escala de grises. Los formatos de las imágenes pueden ser TIFF, PSD o JPG, y deben cumplir con las características expresadas en el punto anterior (figuras).

Planimetría: se debe entregar la planimetría original en medio digital, en lo posible en formato CAD, y sus respectivos archivos de plumas o en PDF; de no ser posible, se deben hacer impresiones en tamaño carta con las referencias de los espacios mediante numeración y lista adjunta. Deben tener escala gráfica, escala numérica, norte, coordenadas y localización. En lo posible, no deben contener textos, achurados o tramas.

Para más detalles, consultar el documento RevArq Parámetros para Autores Descripción en el portal web de la Revista de Arquitectura

\section{Beneficios}

Como reconocimiento a los autores, se les hará envío postal de dos ejemplares de la edición impresa sin ningún costo y entregada en la dirección consignada en el formato de hoja de vida (RevArq FP01); adicionalmente, se enviará el vínculo para la descarga de la versión digital.

También se enviará una constancia informativa en la que se relaciona la publicación del artículo y, de manera opcional, se pueden detallar las fechas del proceso editorial y el arbitraje realizado. 
La selección de revisores se realiza de acuerdo con los siguientes criterios:

- Afinidad temática.

- Formación académica.

- Experiencia investigativa y profesional.

- Producción editorial en revistas similares o en libros resultado de investigación.

El proceso de arbitraje se basa en los principios de equidad e imparcialidad, y en los criterios de calidad y pertinencia.

El desarrollo de la revisión se realiza según el formato (RevArq FP10 Evaluación de artículos) y las observaciones que el revisor considere necesarias en el cuerpo del artículo. En cualquiera de los conceptos que emita el revisor (Aceptar, Publicable con modificaciones, Reevaluable o No publicable), y como parte de la labor formativa y de comunidad académica, el revisor hará sugerencias para mejorar el documento. El revisor podrá solicitar una nueva relectura del artículo después de los ajustes realizados por el autor.

El revisor también deberá diligenciar el formato RevArq FP01 Hoja de Vida, con el fin de certificar y soportar el proceso de revisión ante los SIR que así lo soliciten.

En el proceso de arbitraje se emplea el método doble ciego, los nombres del revisor no serán conocidos por el autor y viceversa. Con el fin de garantizar el anonimato del autor, al artículo postulado se le han podido suprimir nombres, instituciones o imágenes que puedan ser asociadas de manera directa al autor.

Aunque se procura el anonimato, una vez recibida la invitación como par revisor del artículo, el revisor debe cerciorarse de que no exista conflicto de intereses (CDI) o alguna limitante que afecte la revisión o que pueda ser vista como tal (lazos familiares, amistad o enemistad, vínculos contractuales o laborales, posiciones éticas, etc.), de presentarse esta situación se notificara al editor. (Ver modelo RevArq FP06 CDI).

Dada la confidencialidad del proceso de revisión, y considerando los derechos de autor y de propiedad intelectual que pueda haber sobre el material que se entrega, el revisor se compromete a mantener en absoluta reserva su labor, a limitar el uso de la obra entregada solo para el propósito designado y a devolver la documentación remitida una vez concluya la actividad.

El tiempo establecido para las revisiones de pares es de máximo un mes a partir de la confirmación de la recepción de la documentación. Ese plazo podrá ser modificado de mutuo acuerdo entre el editor y el revisor, siempre y cuando no afecte la periodicidad de la revista, la impresión o el tiempo para emitir una respuesta al autor.

Los revisores se acogerán a "COPE Ethical Guidelines for Peer Reviewers" de COPE.

\section{Beneficios}

Como retribución a los revisores se les hará envío postal de un ejemplar de la edición impresa sin ningún costo y entregada en la dirección consignada en el formato de hoja de vida. También, si es de interés para el revisor, podrá hacer la solicitud de alguna de las publicaciones editadas y presentes en el catálogo de publicaciones de la UNIVERSIDAD CATÓlica de Colombia, previa aprobación de la Editorial y sujeto a la disponibilidad.

Si lo desea tendrá derecho a una constancia de la colaboración en la revisión de artículos, la cual solo contendrá el periodo en el cual se realizó la actividad. También tendrá la posibilidad de aceptar o no la publicación de su nombre, nacionalidad y nivel máximo de formación en la página web de la Revista de Arquitectura en su calidad de colaborador.

\section{A) Proceso de revisión por pares}

Luego de la postulación del artículo, el editor de la Revista de Arquitectura selecciona y clasifica los artículos que cumplen con los requisitos establecidos en las directrices para los autores. El editor podrá rechazar en primera instancia artículos, sin recurrir a un proceso de revisión, si los considera de baja calidad o por presentar evidencias de faltas éticas o documentación incompleta.

Los artículos se someterán a un primer dictamen del editor, de los editores de sección y del Comité Editorial, teniendo en cuenta:

- Afinidad temática, relevancia del tema y correspondencia con las secciones definidas.

- Respaldo investigativo.

- Coherencia en el desarrollo del artículo, así como una correcta redacción y ortografía.
- Relación entre las figuras y tablas con el texto del artículo.

En esta revisión se verificará el nivel de originalidad mediante el uso de software especializado (Ithenticate o similar) y recursos digitales existentes para tal fin, también se observará la coherencia y claridad en los apartados del documento (modelo IMRYD), la calidad de las fuentes y la adecuada citación, esto quedará consignado en el formato (RevArq FP09 Revisión de artículos); esta información será cargada a la plataforma de gestión editorial y estará a disposición del autor.

En caso de que el artículo requiera ajustes preliminares, será devuelto al autor antes de ser remitido a revisores. En este caso, el autor tendrá veinte días para remitir nuevamente el texto con los ajustes solicitados.

Después de la preselección se asignan mínimo dos revisores especializados, quienes emitirán su concepto utilizando el formato (RevArq FP10 Evaluación de artículos) y las anotaciones que consideren oportunas en el texto; en esta etapa se garantizará la confidencialidad y el anonimato de autores y revisores (modalidad doble ciego).

Del proceso de revisión se emite uno de los siguientes conceptos que será reportado al autor:

- Aceptar el envío: con o sin observaciones.

- Publicable con modificaciones: se podrá sugerir la forma más adecuada para una nueva presentación, el autor puede o no aceptar las observaciones según sus argumentos. Si las acepta, cuenta con quince días para realizar los ajustes pertinentes.

- Reevaluable: cumple con algunos criterios y debe ser corregido. Es necesario hacer modificaciones puntuales y estructurales al artículo. En este caso, el revisor puede aceptar o rechazar hacer una nueva lectura del artículo luego de ajustado.

- No publicable: el autor puede volver a postular el artículo e iniciar nuevamente el proceso de arbitraje, siempre y cuando se evidencien los ajustes correspondientes.

En el caso de presentarse diferencias sustanciales y contradictorias en los conceptos sobre la recomendación del revisor, el editor remitirá el artículo a un revisor más o a un miembro del Comité Editorial quien podrá actuar como tercer árbitro, con el fin de tomar una decisión editorial sobre la publicación del artículo.

Los autores deberán considerar las observaciones de los revisores o de los editores, y cada corrección incorporada u omitida debe quedar justificada en el texto o en una comunicación adjunta. En el caso que los autores omitan las indicaciones realizadas sin una argumentación adecuada, el artículo será devuelto y no se dará por recibido hasta que no exista claridad al respecto.

El editor respetará la independencia intelectual de los autores y a estos se les brindará el derecho de réplica en caso de que los artículos hayan sido evaluados negativamente y rechazados.

Los autores, con su usuario y contraseña, podrán ingresar a la plataforma de Gestión Editorial, donde encontrarán los conceptos emitidos y la decisi sobre el artículo.

El editor y el Comité Editorial se reservan el derecho de aceptar o no la publicación del material recibido. También se reservan el derecho de sugerir modificaciones de forma, ajustar las palabras clave o el resumen y de realizar la corrección de estilo. El autor conocerá la versión final del texto antes de la publicación oficial del mismo.

Cuando un artículo es aceptado para su publicación, el autor debe firmar la autorización de reproducción (RevArq FP03 Autorización reproducción). Para más información ver: Política de derechos de autor

\section{Notas aclaratorias:}

La Revista de Arquitectura publica un número limitado de artículos por volumen y busca el equilibrio entre las secciones, motivo por el cual, aunque un artículo sea aceptado o continúe en proceso de revisión, podrá quedar aplazado para ser publicado en un próximo número; en este caso, el autor estará en la posibilidad de retirar la postulación del artículo o de incluirlo en el banco de artículos del próximo número.

El editor y los editores de sección de la Revista de Arquitectura son los encargados de establecer contacto entre los autores y revisores, ya que estos procesos se realizan de manera anónima.
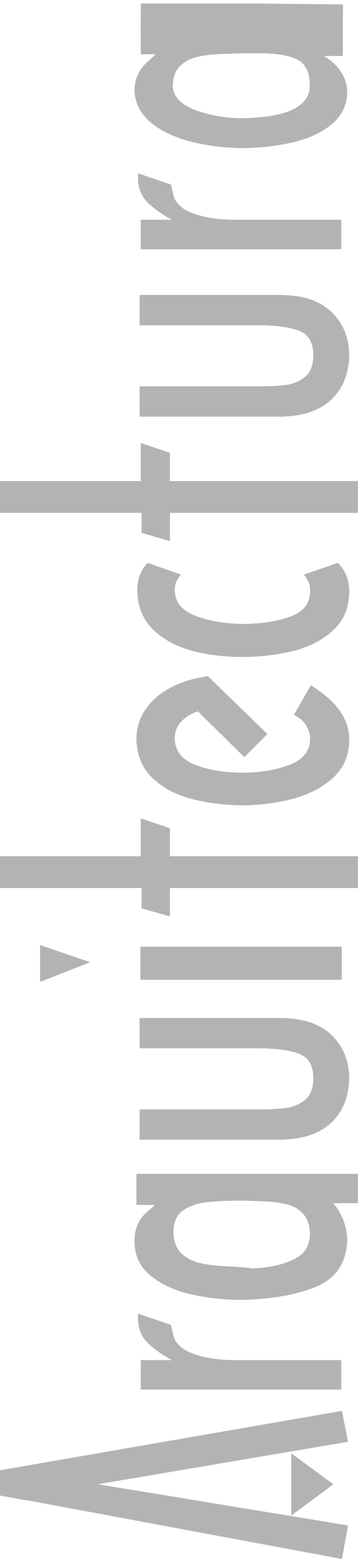
Estructura de indicadores de habitabilidad del espacio público en ciudades latinoamericanas

ن Structure of indicators of public space habitability in Latin American cities

Pablo Páramo,Andrea Burbano, Diana Fernández-Londoño

Além do público/privado

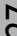
no Rio de Janeiro

Más allá de lo público y lo privado. Intervenciones temporales y creación de espacios colectivos en Río de Janeiro

Beyond the public and the private. temporary interventions and the creation of collective spaces in Rio de Janeiro

Conservar o renovar: dinámicas de histórico de tres

ciudades intermedias patrimoniales

U Una mirada a través de las licencias urbanísticas

To preserve or to renovate: Construction dynamics in the historic center of three intermediate-sized heritage cities. A look through urban planning permits

\section{Lida Buitrago-Campos}

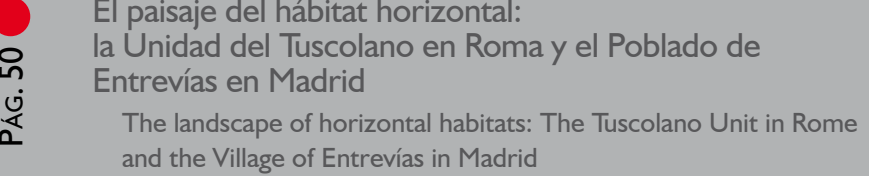

Evolución paralela del relato fílmico y la arquitectura de ㅇ. los cines entre 1900 y 1930

Atención especial al caso españo

¿ Parallel evolution of cinematographic stories and the architecture of cinemas between 1900 and 1930, with a special attention to the Spanish case

\section{Ana C. Lavilla-Iribarren}

El plan, acto mesiánico del proyectista

- La situación histórica del diseño en la utopía

₹. modernizante

The plan, a messianic act of the project architect. The historica situation of design in the modernizing utopia

Resiliencia a inundaciones: nuevo paradigma para el diseño urbano

ن Flood resilience: A new paradigm for urban design

¿ Resilience to flooding: new paradigm to urban design

Luis Fernando Molina-Prieto

Acceso solar en la arquitectura y la ciudad

ผ

Aproximación histórica

Solar access in architecture and the city. Historical approach

这

Campus universitario sustentable

ô

Sustainable university campus

نำ

Lina Johanna Zapata-González,Andrés Quiceno-Hoyos,
Luisa Fernanda Tabares-Hidalgo

La crítica arquitectónica como objeto de investigación

[La critique architecturale, objet de recherche]

Architectural criticism as an object of research

ن் Hélène Jannière 